\title{
EL CONTROL DE LAS OMISIONES LEGISLATIVAS POR EL "BUNDESVERFASSUNGSGERICHT"
}

\author{
FRANCISCO FERNÁNDEZ SEGADO \\ Catedrático de Derecho Constitucional \\ Universidad Complutense de Madrid
}

SUMARIO

I. El "Verfassungsbeschwerde" como instrumento procesal frente a las omisiones

II. El incumplimiento del deber de legislar por el legislador: la omisión legislativa. "La exclusión arbitraria de beneficio"

III. La pluralidad de técnicas decisorias del "BVerfG"

IV. Las decisiones de apelación al legislador ("Apellentscheidung")

V. Las declaraciones de inconstitucionalidad sin nulidad ("Unvereinbarkeitserklärung")

VI. Las decisiones interpretativas o de interpretación conforme a la Constitución ("Verfassungskonforme Auslegung")

"Die Bundesrepublik Deutschland ist (...) nicht nur eine stabile Demokratie, sondern auch ein stabiler, wehrhafter Rechtsstaat geworden" (La República Federal Alemana no sólo es una democracia estable, sino que ha llegado a ser también un Estado de Derecho capaz de defenderse). Es esta una de las conclusiones con las que Scholz finaliza un trabajo realizado con ocasión del cincuentenario del Tribunal Constitucional Federal (BVerfG), en el que trata de dar respuesta al sugestivo interrogante de si el Tribunal es un 
guardián de la Constitución (Hüter der Verfassung) o un legislador sustituto (Ersatzgesetzgeber $)^{1}$. Tal reflexión nos parece muy pertinente para empezar el estudio del control llevado a cabo en Alemania, en sede constitucional, de las omisiones legislativas, por cuanto la evolución seguida al efecto por la jurisprudencia del BVerfG creemos que es un excelente ejemplo de la búsqueda de fórmulas con las que dar una respuesta jurídica, demandada por el Estado de Derecho, a cuyo través poder hacer frente a un problema de más que notable trascendencia constitucional como es el de las lesiones de derechos fundamentales resultantes de las omisiones del legislador.

El Tribunal iba a partir de una posición contraria a la fiscalización de las omisiones legislativas, careciendo además de un instrumental adecuado con el que hacerles frente, no obstante lo cual, progresivamente, iba a ir modulando su posición, primero, admitiendo el recurso de queja constitucional (Verfassungsbeschwerde) como vía procesal adecuada para hacer frente a las omisiones del legislador vulneradoras de derechos fundamentales del recurrente, recurso que más tarde iba asimismo a admitirse frente a sentencias de los órganos jurisdiccionales superiores lesivas de derechos, de resultas, básicamente, de la inexistencia de normas legislativas que diesen plena eficacia a determinadas disposiciones constitucionales. Finalmente, no obstante la específica previsión del art. 100.1 de la Grundgesetz $(\mathrm{GG})^{2}$, el BVerfG ha reconocido la posibilidad de un control concreto incidental de las omisiones del legislador. Es por todo ello por lo que se ha podido afirmar, con evidente razón, que el caso alemán es un buen ejemplo de cómo superar objeciones de tipo procesal para proporcionar a los ciudadanos protección jurisdiccional en supuestos de omisión inconstitucional ${ }^{3}$.

El análisis del control de las omisiones del poder legislativo por el Bundesverfassungsgericht exige atender a dos cuestiones diferenciadas: la primera de ellas es la del instrumento procesal utilizado para hacerles jurídicamente frente; la segunda, la de las técnicas decisorias a las que el BVerfG ha recurrido para el control de las omisiones del legislador.

1 Rupert ScHOlz: "Das Bundesverfassungsgericht: Hüter der Verfassung oder Ersatzgesetzgeber?", en Aus Politik und Zeitgeschichte, Band 16/1999, págs. 3 y ss.; en concreto, pág. 8.

$2 \mathrm{El}$ art. 100.1 GG contempla un instituto procesal análogo al de la cuestión de inconstitucionalidad del art. 163 de la Constitución española, refiriéndose específicamente a que el tribunal debe considerar inconstitucional "una ley" (Hält ein Gericht "ein Gesetz"...") de cuya validez ha de depender la decisión ("auf dessen Gültigkeit es bei der Entscheidung ankommt"). Obviamente, ello presupone que el planteamiento de la cuestión venga referido a una ley vigente, no a una omisión legislativa.

3 Jorge PEREIRA DA Silva: Dever de legislar e protecção jurisdicional contra omissões legislativas, Universidade Católica Editora, Lisboa, 2003, pág. 190. 


\section{EL «VERFASSUNGSBESCHWERDE» COMO INSTRUMENTO PROCESAL FRENTE A LAS OMISIONES}

I. El art. 92 de la Gesetz über das Bundesverfassungsgericht (Ley del Tribunal Constitucional Federal) (BVerfGG) ${ }^{4}$, al contemplar la fundamentación de la queja ("der Begründung der Beschwerde"), esto es, del recurso de queja constitucional (Verfassungsbeschwerde), exige que se especifique el derecho presuntamente vulnerado y la acción u omisión de los órganos o autoridad ("die Handlung oder Unterlassung des Organs oder der Behörde") por la que se sienta lesionado el recurrente. Quiere ello decir que, a diferencia de lo que se prevé respecto del control normativo abstracto y concreto o incidental, en el recurso de queja se alude de modo específico a la posible lesión de derechos derivada de una omisión. Más aún, el art. 95.1 BVerfGG determina que si se estimare el recurso de queja constitucional, se hará constar en la resolución ( in der Entscheidung") qué prescripción de la Ley Fundamental ("welche Vorschrift der Grundgesetzes") y a través de qué acción u omisión (und durch welche Handlung oder Unterlassung") han sido violados. Tal norma no hace sino corroborar lo anteriormente dicho: también por intermedio de una omisión puede conculcarse la GG, particularmente en lo que a los derechos fundamentales atañe.

La doctrina, ya a los pocos años de vida del Tribunal, se ocupaba con cierto detalle de la cuestión de la admisibilidad de los recursos de queja frente a lesiones de derechos fundamentales por omisiones del legislador ${ }^{5}$, suscitándose como tema bien conexo con el precedente el de la posibilidad de configurar un derecho público subjetivo a un comportamiento activo del legislador, derecho, por lo general, siempre rechazado. Kalkbrenner se plantearía asimismo la cuestión de las omisiones del poder reglamentario («Unterlassen des Verordnungsgebers" $)^{6}$, o lo que es igual, si cabía una coercibilidad para dictar este tipo de normas reglamentarias ("der Erzwingbarkeit der Erlassen einer solchen Verordnung") en aquellos casos en que hubiera una violación (por omisión) de derechos fundamentales. A su juicio, era opinión reconocida que el individuo, a través del Verfassungsbeschwerde, podía buscar una actuación del poder reglamentario ("ein Handeln des Verordnungsgebers").

También en los años sesenta, Denninger, aún admitiendo el cauce del recurso de queja constitucional para combatir las omisiones del legislador vul-

4 Como es bien sabido, la BVerfGG es de 12 de marzo de 1951. Nosotros manejamos el texto de la Bundesverfassungsgerichtsgesetz en la versión promulgada el 11 de agosto de 1993. Puede verse en la obra Grundgesetz, Menschenrechtskonvention, Europäischer Gerichtshof, Bundesverfassungsgerichtsgesetz, Parteiengesetz, Untersuchungsausschussgesetz, 41. Auflage, Deutscher Taschenbuch Verlag, München, 2007, págs. 145 y ss.

5 Tal es el caso, por ejemplo, de SEIwERTH: Zur Zulässigkeit der Verfassungsbeschwerde gegenüber Grundrechtsverletzungen des Gesetzgebers durch Unterlassen, Berlin, 1962. Asimismo, Helmut KALKBRENNER: "Verfassungsauftrag und Verpflichtung des Gesetzgebers", en Die Öffentliche Verwaltung (DÖV), 16. Jahrgang, Heft 2, Januar 1963, págs. 41 y ss.

6 Helmut KalkBrenner: "Verfassungsauftrag und Verpflichtung...”, op. cit., págs. 50-51. 
neradoras de un derecho fundamental, se inclinaba a favor de ciertas cautelas para que el BVerfG pudiera constatar de modo efectivo la existencia de una violación constitucional. La comprobación de una lesión constitucional a través de la omisión («Bei der Feststellung einer Verfassungsverletzung durch Unterlassen") — razonaba Denninger — se ha de tomar en consideración de forma seria en razón de la libertad dispositiva de los legisladores ("der gesetzgeberischen Dispositionsfreiheit»), del carácter político de la formación de la voluntad ("den politischen Charakter der Willensbildung") y, en muchos casos, también de resultas del carácter programático de los mandatos constitucionales ("der Plancharakter der Verfassungsauftrages"). Incluso un autor como Friesenhahn, que en el bien conocido e importante Coloquio Internacional de Heidelberg sobre la justicia constitucional celebrado en 1961, se mostraba, por principio, contrario a que un recurso de queja constitucional contra una omisión del legislador pudiera ser tomado en consideración ${ }^{8}$, de inmediato matizaba su opinión al razonar que, a la vista de que la Grundgesetz da al legislador el encargo de dictar determinadas leyes, conectadas con el principio del Estado social (Sozialstaatsprinzips), como, por ejemplo, el art. 33.5, que encomienda al legislador la regulación del régimen jurídico de la función pública ("das Recht des öffentlichen Dienstes") con respeto a los principios tradicionales de la profesión funcionarial ("der hergebrachten Grundsätze des Berufsbeamtentums»), una omisión del legislador que violara el principio de igualdad o los derechos tradicionales del empleo público, podía ser hecha valer a través del Verfassungsbeschwerde?. Friesenhahn admitía finalmente que el BVerfG había compendiado su opinión ("seine Auffassung") al respecto en el siguiente axioma ("LeitsatZ"): "Si el legislador realiza tan sólo parcialmente la tarea de promulgar unas determinadas leyes, a consecuencia de una interpretación inexacta de la Ley Fundamental («unrichtiger Auslegung des Grundgesetzes"), y viola, a través de la no consideración de todas las circunstancias ("durch die Nichtberücksichtigung"), los derechos fundamentales del art. 3. GG de determinados sectores de la población ("eines bestimmten Bevölkerungskreises Grundrechte aus Art. 3 GG»), puede ser interpuesto contra su omisión un recurso de queja constitucional ${ }^{10}$. En definitiva, Friesenhahn, que, recordémoslo, fuera juez del Tribunal Constitucional Federal, compendiaba el criterio al respecto del propio Tribunal en la posición proclive de éste a conocer, a través de un recurso de queja constitucional, de las que casi un

7 Erhard Denninger: "Verfassungsauftrag und gesetzgebende Gewalt", en Juristenzeitung (JZ), nummer 23/24, 9. Dezember 1966, págs. 767 y ss.; en concreto, pág. 772.

8 Eine Verfassungsbeschwerde —escribe Friesenhahn - gegen ein Unterlassen des Gesetzgebers kommt grundsätzlich nich in Betracht". Ernst FriEsEnHAHN: "Die Verfassungsgerichtsbarkeit in der Bundesrepublik Deutschland", en Verfassungsgerichtsbarkeit in der Gegenwart (Länderberichte und Rechtsvergleichung), Herausgegeben von Hermann MosLer, (Max-Planck-Institut für Ausländisches Öffentliches Recht und Völkerrecht), Carl Heymanns Verlag KG, Köln/Berlin, 1962, págs. 89 y ss.; en concreto, pág. 149.

9 Ibidem, pág. 150.

10 Ibidem, pág. 150. 
decenio antes otro juez constitucional, Wessel, había tildado de relatives Unterlassen, contraponiéndolas, a las Absolutes Unterlassen des Gesetzgebers ${ }^{11}$. No era una posición la suya especialmente novedosa.

$\mathrm{Al}$ analizar los diversos aspectos del recurso de queja constitucional frente a las omisiones del legislador, la doctrina no ha albergado la más mínima duda acerca de la obligatoriedad que para el poder legislativo tiene el cumplimiento de una sentencia constitucional de inconstitucionalidad omisiva. Una sentencia dictada en el marco de un recurso de queja constitucional - escribe Schenke en su amplio estudio sobre las garantías jurídicas frente a las omisiones de normas jurídicas ${ }^{12}$ — obliga al legislador a través de la realización de la ley ("durch Vornahme des Gesetzes") a eliminar las omisiones inconstitucionales.

En fin, por aludir a algún otro problema que se ha suscitado en torno al tema que nos ocupa, la doctrina se ha planteado la cuestión de la vigencia del principio de la subsidiariedad del recurso de queja en los supuestos omisivos de normas. Como es bien sabido, y constituye jurisprudencia constante, el recurso de queja no es un recurso adicional, esto es, un instrumento procesal adicional a los existentes ante los jueces y tribunales ordinarios con vistas a recabar la tutela de un derecho supuestamente transgredido; por el contrario, se trata de un recurso extraordinario para la tutela de los "Grundrechte", de los derechos fundamentales (al margen ya de algunos otros a los que alude de modo específico el art. 93, 4 a/ de la Ley Fundamental, tras la reforma introducida en ella por la Ley de 29 de enero de 1969), frente a transgresiones de los mismos llevadas a cabo por los poderes públicos. Es por ello mismo por lo que Weber ha podido afirmar ${ }^{13}$ que el Verfassungsbeschwerde no es un recurso en sentido procesal, sino un remedio jurídico autónomo, y así, para el recurso de queja constitucional es característica la función subsidiaria respecto a los recursos ordinarios. Pues bien, Detterbeck se iba a plantear la cuestión de si ese principio procesal de subsidiariedad podía predicarse asimismo de las omisiones normativas ${ }^{14}$. A su juicio ${ }^{15}$, la presentación inmediata de los

11 Wessel: "Die Rechtsprechung des Bundesverfassungsgerichts zur Verfassungsbeschwerde", en Deutsches Verwaltungsblatt (DVBl), 67. Jahrgang, Heft 6, 15. März 1952, págs. 161 y ss.; en particular, pág. 164.

12 Wolf-Rüdiger SCHENKE: "Rechtsschutz gegen das Unterlassen von Rechtsnormen", en Verwaltungs-Archiv (VerwArch), 82. Band, Heft 3, 1. Juli 1991, págs. 307 y ss.; en concreto, pág. 327

13 Albrecht Weber: "La Jurisdicción Constitucional de la República Federal de Alemania", en Anuario Iberoamericano de Justicia Constitucional, n. ${ }^{\circ}$ 7, 2003, págs. 495 y ss.; en concreto, pág. 514. En su versión original, cfr. Albrecht WeBER: "Die Verfassungsgerichtsbarkeit in der Bundesrepublik Deutschland, en Verfassungsgerichtsbarkeit in Westeuropa, Christian STARCK und Albrecht Weber (Hrsg.), 2. Auflage, teilband I (Berichte), Nomos, Baden-Baden, 2007, págs. 37 y ss. "Die Verfassungsbeschwerde — escribe Weber (pág. 52)— ist daher nicht ein Rechtsmittel im Sinne der Prozessordnung, sondern ein eigenständiger Rechtsbehelf".

14 Steffen DetTerbecK: "Subsidiarität der Verfassungsbeschwerde nach Art. 93 Abs. 1 Nr. 4 a GG auch bei normativem Unterlassen?", en Die Öffentliche Verwaltung (DÖV), Heft 20, Oktober 1990, págs. 858 y ss.

15 Ibidem, pág. 864. 
recursos de queja constitucionales por omisiones ("die Erhebung sofortiger Unterlassensbeschwerden") formalizados de conformidad con el $n .^{\circ} 4$ a) del art. 93.1 GG fracasa a causa de la necesidad de agotamiento de la vía judicial ("Rechtswegerschöpfung") del inciso primero del art. 90.2 de la Ley del Tribunal Constitucional Federal (BVerfGG) ${ }^{16}$. En definitiva, como el mismo autor escribe poco más adelante ${ }^{17}$, la inmediatez del recurso fracasa de resultas del principio general de subsidiariedad por el que se rige el recurso de queja constitucional ("der allgemeinen Subsidiarität der Verfassungsbeschwerde").

II. El Tribunal Constitucional Federal bien pronto iba a tener que enfrentarse con el problema de las omisiones inconstitucionales del legislador. Ello iba a acontecer en la Sentencia de 19 de diciembre de 1951, en la que el BVerfG se pronuncia acerca de un recurso de queja constitucional. Un ciudadano inutilizado para trabajar y privado de otros medios de subsistencia, salvo una mínima pensión mensual para mantener a sus tres hijos menores de edad, recurría ante el BVerfG, reclamando del juez constitucional que se pronunciara en el sentido de que el legislador, al no asegurar una más adecuada y decorosa subsistencia, había violado diferentes derechos fundamentales proclamados en la Ley Fundamental, y en particular, los garantizados por el art. 1. ("die Würde des Menschen", la dignidad de los hombres), 2. ("Recht auf die freie Entfaltung seiner Persönlichkeit", el derecho al libre desarrollo de su personalidad) y 3. ${ }^{\circ}$ ("Alle Menschen sind vor dem Gesetz gleich", igualdad de todos los hombres ante la ley). El recurrente en queja demandaba además al BVerfG que determinase la obligación del Gobierno federal de presentar un proyecto de ley para la modificación de la hasta ese momento vigente legislación.

El BVerfG reconoció en la mencionada sentencia que de la sujeción a la Constitución, y muy particularmente a los Grundrechte, podían surgir para los órganos judiciales y administrativos concretas obligaciones de actuar, cuya inobservancia podía conducir a una auténtica omisión inconstitucional lesiva de derechos fundamentales. Sin embargo, en la misma decisión, el Tribunal, en línea de principio, excluyó que una inacción del legislador pudiera dar lugar a una omisión inconstitucional ${ }^{18}$. No obstante ese fallo, Lechner, al margen ya de alguna otra consideración ${ }^{19}$, ponía de relieve que el hecho de que el

16 A tenor del inciso primero del art. 90.2 BVerfGG: "Ist gegen die Verletzung der Rechtsweg zulässig, so kann die Verfassungsbeschwerde erst nach Erschöpfung des Rechtswegs erhoben werden" [Si contra la infracción — se refiere a toda lesión de derechos fundamentales causada por un poder público ("durch die öffentliche Gewalt") — fuese admisible la vía judicial, sólo podrá formularse el recurso de queja constitucional después de agotada la vía judicial].

17 Steffen DetTerbeck: "Subsidiarität der Verfassungsbeschwerde...", op. cit., pág. 864.

18 Nicolò TROCKER: "Le omissioni del legislatore e la tutela giurisdizionale dei diritti di libertà (Studio comparativo sul diritto tedesco)" en Archivio Giuridico "Filippo Serafini", volume CLXXVIII, Fascicoli 1-2, Gennaio/Aprile 1970, págs. 88 y ss.; en concreto, págs. 100-101.

19 Subraya Lechner que la Sentencia de 19 de diciembre de 1951 deja claro que la inadmisibilidad de los recursos de queja constitucional frente a omisiones del legislador, absolutas y relativas, ("Die Unzulässigkeit von Verfassungsbeschwerden gegen —absolute und relativeUnterlassungen des Gesetzgebers") no podría, por ejemplo, derivarse del art. 95 BVerfGG. Dr. LECHNER: "Zur Zulässigkeit der Verfassungsbeschwerde gegen Unterlassungen des Gesetzgebers", 
Tribunal no reconociera la posibilidad de una inconstitucionalidad por omisión del legislador, no entrañaba que el legislador no debiese extraer, en el ámbito de sus competencias y de sus facultades legislativas, las conclusiones necesarias de una sentencia como ésta ${ }^{20 / 21}$.

En último término, la sentencia a la que nos acabamos de referir lo que parecía estar vedando como objeto de fiscalización en sede constitucional era tan sólo la omisión absoluta del legislador, cual era por cierto el caso, pero no la omisión relativa. Esa vendría a ser la interpretación asumida por algunos autores $^{22}$.

El primer litigio verdaderamente relevante en torno a la omisión legislativa iba a venir desencadenado por la cláusula del art. 117.1 GG, de conformidad con la cual, las disposiciones que se opusieran al art. 3. . 2 de la propia Grundgesetz (principio de igualdad de derechos entre hombres y mujeres: "Männer und Frauen sind gleichberechtigt") podían permanecer en vigor hasta la adaptación a dicho precepto de la Grundgesetz, pero en ningún caso más allá del 31 de marzo de 1953. Se trataba, pues, de dar un margen de tiempo al legislador para que acomodase la legislación en vigor a ese principio de igualdad de género. Ante la omisión del legislador, transcurrido el plazo constitucionalmente preestablecido, el BVerfG iba a declarar la plena eficacia de la cláusula de igualdad del art. 3. .2, con la subsiguiente derogación de toda norma que la conculcase. Con ello, como dijera Picardi ${ }^{23}$, la jurisprudencia asumía la función de rellenar las lagunas (nosotros más bien hablaríamos de suplir las omisiones) y de convertir en plenamente operativa desde el punto de vista jurídico una norma que, hasta ese momento, se entendía que requería para su plena eficacia la interpositio legislatoris.

Será en los años 1957 y 1958 cuando el BVerfG, en sus decisiones de 20 de febrero de 1957 y 11 de junio de 1958, dictadas ambas en sendos recursos de queja constitucional, abandonando sus primeras tomas de posición (particularmente, la que parecía frontal oposición de la sentencia de diciembre de 1951, si bien, como ya se ha expuesto, esa oposición se dirigía hacia la omisión absoluta del legislador), admitía de modo inequívoco que la inconstitu-

en Neue Juristische Wochenschrift (NJW), 8. Jahrgang, Heft 49, 9. Dezember 1955, págs. 1817 y ss.; en concreto, pág. 1819.

20 Ibidem, pág. 1819.

21 De la importancia de esta sentencia se hacía eco Mauro CAPPELLETTI, en su clásica obra La giurisdizione costituzionale delle libertà (Primo studio sul ricorso costituzionale), Giuffrè Editore, Milano, 1955, pág. 82.

22 Entre ellos, Wessel, en su ya clásico artículo, "Die Rechtsprechung des Bundesverfassungsgerichts zur Verfassungsbeschwerde", op. cit., pág. 164, y aún más claramente Cappelletti, quien escribe al respecto: "quanto invece alle omissioni del legislatore, la giurisprudenza del Tribunale federale costituzionale - ricordo soprattutto un'importante pronuncia del 19 dicembre 1951- è finora nel senso che esse possano essere oggetto di ricorso solo nel caso che si tratti di "omissioni relative"...". Mauro CAPPELLETTI: La giurisdizione costituzionale delle libertà, op. cit., pág. 82.

23 Nicola PICARDI: "Le sentenze "integrative" della Corte costituzionale", en Aspetti e tendenze del Diritto costituzionale. Scritti in onore di Costantino Mortati, Giuffrè Editore, Milano, 1977, vol. $4 .^{\circ}$, págs. 597 y ss.; en concreto, pág. 616. 
cionalidad podía provenir no sólo por vía de acción, sino también por vía de la omisión legislativa.

El Tribunal Constitucional Federal admitía la posibilidad de tal quiebra constitucional por inacción en los supuestos de omisión parcial del legislador en los que éste, al contemplar en el texto legal tan sólo a un grupo o fragmento de población, podía quebrar el principio de igualdad. Se daban así los primeros pasos para el reconocimiento dogmático de la llamada "exclusión arbitraria de beneficio" inconstitucional (willkürlicher gleichheitswidriger Begünstigungsausschluss), por vulneración del principio de igualdad, en cuanto, en último término, entrañaba una discriminación en el goce de uno o más derechos de un grupo respecto de otro.

En la segunda de sus sentencias, la de 11 de junio de 1958, el Tribunal Constitucional Federal se pronunció sobre un recurso de queja planteado frente a una ley federal que establecía la remuneración de los funcionarios públicos. El Tribunal se manifestó en el sentido de que aunque no estuviese legitimado para fijar los sueldos de los funcionarios, disponía de elementos suficientes como para apreciar que, en virtud de la alteración del coste de la vida, los valores establecidos por tal ley no se correspondían a los parámetros mínimos a que se refiere el art. 33.5 de la Grundgesetz, al que ya hemos aludido en un momento anterior. El BVerfG no declaró la nulidad de la norma, porque de la misma no se hubiera derivado sino un agravamiento del estado de inconstitucionalidad, limitándose por tanto a constatar la violación constitucional. Con esta doctrina, el BVerfG identificó muy tempranamente que omisión inconstitucional era no sólo el incumplimiento absoluto de la obligación de legislar, sino también la ejecución defectuosa o incompleta de ese mismo deber (omisión relativa, aunque también omisión parcial o Teilunterlassung) ${ }^{24}$.

Estas tomas de posición jurisprudencial marcaban una pauta diferencial más que notable respecto de años anteriores. Kalkbrenner así lo destacaba al constatar en $1963^{25}$ que al problema de las omisiones del legislador se estaba prestando creciente atención en los últimos años tanto por parte de la jurisprudencia ("Rechtsprechung") como de los escritos o literatura jurídica ("Schrifftum"), lo que no había acontecido en la época de la República de Weimar ("die Zeit der Weimarer Republik"), en la que prevaleció la opinión de la "Soberanía y el autoritarismo del legislador" (Souveranität und Selbstherrlichkeit des Gesetzgebers"). Recordemos el mayoritario rechazo de la vinculación del legislador a los derechos fundamentales durante la época de Weimar. En esta etapa, para el legislador, los derechos tan sólo valían como líneas orientativas, tanto por su indeterminación material, como por la idea de la soberanía del legislador estatal recibida del positivismo jurídico-público ${ }^{26}$.

24 Cfr. al efecto, Gilmar FERREIRA MENDES: "O controle da omissão inconstitucional", en Jairo SCHÄFER (organizador), Temas polêmicos do constitucionalismo contemporâneo, Conceito Editorial, Florianópolis, 2007, págs. 137 y ss.; en concreto, pág. 142.

25 Helmut KaLKBRENNER: “Verfassungsauftrag und Verpflicht des Gesetzgebers”, op. cit., pág. 41.

26 Ernst-Wolfgang BÖCKENFÖRDE: Escritos sobre Derechos Fundamentales, Nomos Verlagsgesellschaft, Baden-Baden, 1993, pág. 97. 
Particularísima trascendencia iba a tener la Sentencia de 29 de enero de 1969. Recordaremos ahora que al estimar el recurso de queja constitucional interpuesto frente a la decisión del Tribunal regional de Kiel, de priorizar la aplicación de varias disposiciones preconstitucionales del Código Civil, aun cuando ello se tradujera en una violación del principio de igualdad de los hijos habidos fuera del matrimonio ("den unehelichen Kindern") respecto de los hijos matrimoniales ("den ehelichen Kindern"), sobre las propias cláusulas constitucionales, y en particular sobre el art. $6 .^{\circ} .5 \mathrm{GG}$, que aún no había sido objeto del correspondiente desarrollo constitucional, el Tribunal Constitucional Federal, a la vista de la demora del legislador en el supuesto concreto, entendió que no era exagerado suponer que se había llegado a la fecha del plazo adecuado o razonable si el legislador, veinte años después de la entrada en vigor de la Ley Fundamental, todavía no se había pronunciado sobre las normas de una parte fundamental de la vida como son las que contempla el art. $6 .^{\circ} .5 \mathrm{GG}$, pese a haber aprobado en el mismo período de tiempo numerosas leyes que, desde el punto de vista constitucional, eran mucho menos significativas y urgentes. Pero al margen de ello, el BVerfG iba a entender que una vez transcurrido el "plazo razonable" asegurado al Parlamento para el cumplimiento del deber constitucional de legislar, al tratarse de una norma constitucional bastante precisa, los jueces y tribunales ordinarios podían (más bien habría que decir debían) aplicar la norma constitucional directamente. Con tal doctrina, en último término, el BVerfG estaba reiterando la jurisprudencia que ya había establecido respecto al principio de igualdad de hombres y mujeres (art. 3. ${ }^{\circ} .2$ GG en su conexión con el art. 117.1 también de la Ley Fundamental).

Con la reiteración de esta doctrina, iba a quedar nítidamente clara la obligación del legislador de actuar, aunque, según Trocker ${ }^{27}$, subsistía la cuestión de cómo forzar al legislador a hacerlo. En 1970, el mismo autor aventuraba una solución alternativa con apoyo en el art. 35 BVerfGG, de acuerdo con el cual: "El Tribunal Constitucional Federal puede decidir en su resolución ("Das Bundesverfassungsgericht kann in seiner Entscheidung bestimmen") quién habrá de ejecutarla ("wer sie vollstreckt"), y puede también en el caso concreto ("es kann auch im Einzelfall") regular el modo y la manera (la forma) de la ejecución" ("die Art und Weise der Vollstreckung regeln"). A juicio del profesor del Instituto de Derecho comparado de Firenze, la cláusula en cuestión autorizaba al Tribunal a adoptar de oficio todas las medidas necesarias para asegurar la eficacia de sus propios pronunciamientos.

Se ha especulado asimismo con la posibilidad de acudir a medidas provisionales, al amparo del art. 32 BVerfGG, medidas que se adoptan a solicitud ( «auf Antrag») de parte. Erichsen ha estudiado detenidamente la cuestión ${ }^{28}$. A

27 Nicolò Trocker: "Le omissioni del legislatore e la tutela giurisdizionale dei diritti di libertà”, op. cit., pág. 127.

28 Hans-Uwe ERICHSEN: "Die Einstweilige Anordnung", en Bundesverfassungsgericht und Grundgesetz (Festgabe aus Anlaß des 25 jährigen Bestehens des Bundesverfassungsgerichts), he- 
su juicio, el BVerfG puede regular en ciertos litigios una situación temporal a través de medidas provisionales («einen Zustand durch einstweilige Anordnung vorläufig regeln"). Puede tratarse de una situación jurídica o también de una situación de hecho ("einen tatsächlichen Zustand") en la que no sólo estén afectados los intereses del recurrente, sino en la que también intervengan otras personas. Recuerda Erichsen ${ }^{29}$ que el Tribunal habla de «implicados o interesados en las circunstancias" "Sachverhalts-Beteiligten"). Innecesario es decir que nos hallamos ante medidas cautelares con las que se trata de asegurar la efectividad de la decisión final.

Digamos ante todo que las medidas provisionales a que acabamos de aludir poco o nada tienen que ver con las previsiones del art. 35 BVerfGG, pensadas para la ejecución de la decisión final dictada en sede constitucional. Por lo mismo, no vemos que el recurso a tales medidas tenga ninguna operatividad con vistas al problema precedentemente suscitado. Y más allá de las específicas indicaciones que el Tribunal pueda dirigir, en los casos y términos que más adelante veremos, a los órganos jurisdiccionales ordinarios, a fin de que lleven a cabo una intervención paliativa hasta tanto medie la intervención del legislador hasta entonces inactivo, que sí que podrían tener encaje en el art. 35 BVerfGG, no vemos en absoluto que el Tribunal pueda "forzar", por utilizar la expresión de Trocker ("come forzare il legislatore ad agire"), al legislador a actuar. A lo más que podrá llegar es a volver a declarar la inconstitucionalidad de la omisión si ésta subsiste tras su primera decisión y, obviamente, si es instado para que se pronuncie al efecto, no de resultas de una pura actuación "de oficio".

\section{EL INCUMPLIMIENTO DEL DEBER DE LEGISLAR POR EL LEGISLADOR: LA OMISIÓN LEGISLATIVA. LA «EXCLUSIÓN ARBITRARIA DE BENEFICIO"}

I. El deber de legislar, como es evidente por lo demás, deriva en primer término de una expresa exigencia o mandato constitucional (Verfassungsauftrag), aunque tal deber puede extraerse asimismo de principios desarrollados a través de la interpretación constitucional. En sintonía con todo ello, estamos ante una omisión legislativa relevante, aun cuando ello no entrañe sin más que también sea inconstitucional, cuando ese deber de legislar es omiso.

En relación a los derechos fundamentales, ha tenido una notable relevancia, en lo que ahora interesa, la llamada "teoría de la sustancialidad" (Wesentlichkeitstheorie), en la que el Tribunal estableció que la protección de los derechos fundamentales era el mandato prioritario que recaía sobre el legis- 
lador. Ello, como escribe Scholz ${ }^{30}$, no sólo era relevante en el plano de la delimitación atributiva entre el Legislativo y el Ejecutivo, sino que también lo era, y mucho, respecto a la cuestión que ahora nos ocupa, esto es, la asunción de un deber de legislar por el legislador.

El deber de protección del legislador (Schutzpflicht) obliga al Estado a actuar en defensa y protección de ciertos valores y derechos, como la vida, la integridad física, el honor..., de modo muy particular frente a las agresiones llevadas a cabo por terceros ${ }^{31}$. En ocasiones, y en relación a estos deberes de protección que recaen sobre el poder legislativo, el Tribunal Constitucional Federal, tras reconocer en su decisión la constitucionalidad del texto legal, ha incluido en la parte dispositiva de la decisión una recomendación para que el legislador dicte una disposición supletoria o complementaria. Así, por poner un ejemplo, en una decisión dictada sobre el régimen de la pensión alimenticia debida por los cónyuges en caso de separación, el Tribunal declaró la constitucionalidad de diversos preceptos introducidos en el Código Civil por la ley de reforma del régimen jurídico del matrimonio. Sin embargo, en la parte dispositiva de la sentencia estableció que el legislador, de conformidad con los fundamentos de la propia decisión, debía promulgar las normas complementarias necesarias para evitar un estado de flagrante injusticia («ungerechtfertigte Härten"), fórmula que, como recuerda Ferreira Mendes ${ }^{32}$, fue utilizada asimismo en la decisión de 15 de diciembre de 1983, sobre la ley de empadronamiento, a la que nos referiremos de inmediato.

Más recientemente, el BVerfG ha identificado un deber de adecuación del legislador (Nachbesserungsvorbehalt) ${ }^{33}$. Suele citarse la Sentencia de 8 de agosto de 1978, relativa al reactor nuclear de Kalkar ("Kalkar-Beschluss") como paradigmática en la identificación de este deber. En ella, el BVerfG reconoció que, en virtud de los nuevos desarrollos científicos, el legislador estaba constitucionalmente obligado a un reexamen en favor del uso pacífico de la energía atómica. Analizando diferentes recursos de queja constitucional interpuestos por habitantes de la región próxima a las instalaciones nucleares, el BVerfG resolvió que: «En el supuesto de que se constaten indicios de peligro provenientes de reactores nucleares del tipo "Schneller Brüter" (...), el legislador está obligado a promulgar las nuevas medidas que se requieran". Y un pronunciamiento en similar dirección sería el de 14 de enero de 1981, sobre la polución sonora causada por los aviones.

30 Rupert Scholz: "Alemania: cincuenta años de la Corte Constitucional Federal", en Anuario de Derecho Constitucional Latinoamericano (Konrad Adenauer Stiftung), 2002, págs. 57 y ss.; en concreto, pág. 64

31 Sobre el deber de protección jurídica de los derechos fundamentales y la "Drittwirkung der Grundrechte", cfr. Eckart KLEIN: "Grundrechtliche Schutzpflicht des Staates", en Neue Juristische Wochenschrift (NJW), 42. Jahrgang, Heft 27, 5. Juli 1989, págs. 1633 y ss.; en concreto, págs. 1639-1640.

32 Gilmar FerReira MENDEs: Jurisdição Constitucional (O controle abstrato de normas no Brasil e na Alemanha), 5. ${ }^{\text {a }}$ edição, Editora Saraiva, São Paulo, 2005, pág. 303.

33 Cfr. al efecto, Gilmar FERREIRA MENDES: "O apelo ao legislador (Appellentscheidung) na práxis da Corte Constitucional Federal Alemã", en Revista da Faculdade de Direito da Universidade de Lisboa, vol. XXXIII, 1992, págs. 265 y ss.; en concreto, págs. 291-293. 
Particular relevancia tendría asimismo la decisión, antes mencionada, de 15 de diciembre de 1983, sobre la constitucionalidad de la ley de empadronamiento; en ella, el BVerfG se vio obligado a reconocer la existencia de un deber de adecuación inmediato, independientemente de cualquier otra consideración. Tras entender que los preceptos de la ley del censo de 1982 eran conformes a la Constitución, el Tribunal matizaba que, ello no obstante, en consonancia con los fundamentos jurídicos de la decisión, el legislador debía adoptar las medidas necesarias para la aprobación de las normas complementarias pertinentes a la organización y al procedimiento censal. Esta decisión suponía que el Tribunal declarara la constitucionalidad de la ley una vez que fueran rellenadas las omisiones relativas a la organización y procedimiento censales, lo que, de hecho, más bien parecía entrañar una declaración de inconstitucionalidad que de conformidad constitucional. Sachs vino a equiparar tal decisión a una declaración de inconstitucionalidad sujeta a condición suspensiva, aludiendo a cómo en los fundamentos de esta sentencia podía apreciarse el discurso de compatibilidad ("die Rede von der Vereinbarkeit") con la condición de una regulación complementaria («mit der Maßgabe» der Ergänzungsregelung, ${ }^{34}$.

II. En el mismo plano de los derechos fundamentales (Grundrechte), la trascendencia del principio de igualdad del art. 3. ${ }^{\circ} \mathrm{GG}$ iba a ser enorme. En relación a ese principio ha de visualizarse la construcción dogmática de la "exclusión arbitraria de beneficio", que, como ya se ha expuesto, se produce cuando una disposición propicia una disparidad de tratamiento que se traduce en la exclusión de una determinada categoría de sujetos de entre los beneficiarios de una ley.

Innecesario es decir que la fiscalización de las omisiones relativas o, si así se prefiere, parciales, iba a ampliar notabilísimamente las perspectivas del control de constitucionalidad. El BVerfG, aún orientándose, a modo de principio, por la definición negativa de los efectos esenciales derivados del principio de igualdad, entendida como "prohibición de arbitrio", según una conocida fórmula desarrollada desde tiempo atrás por el Tribunal Federal suizo $^{35}$, iba, sin embargo, a extraer de tal principio un contenido asimismo positivo, en perfecta sintonía, por lo demás, con la fórmula manejada en el texto del Proyecto de la Ley Fundamental de Bonn: «el legislador debe tratar igualmente lo igual y de modo correspondiente lo desigual». En esta visión positiva del principio de igualdad latía una obligación positiva de normas, y en ello ha de atisbarse el presupuesto sustancial de la omisión legislativa. Es verdad que la libertad de configuración y la correlativa "prerrogativa de estimación" (Einschätzungsprärogative) a la que alude Schneider ${ }^{36}$ se traducen en

34 Michael SACHS: "Tenorierung bei Normenkontrollentscheidungen des Bundesverfassungsgerichts", en Die Öffentliche Verwaltung (DÖV), 35. Jahrgang, Heft 1, Januar 1982, págs. 23 y ss.; en concreto, pág. 29.

35 Nicolò Trocker: "Le omissioni del legislatore e la tutela giurisdizionale dei diritti...", op. cit., pág. 111.

36 Hans-Peter SCHNEIDER: "Jurisdicción constitucional y separación de poderes", en Revista Española de Derecho Constitucional, n. ${ }^{\circ}$ 5, Mayo/Agosto 1982, págs. 35 y ss.; en concreto, pág. 51. 
que el legislador esté llamado no sólo a elegir aquellas situaciones objetivas a las que quiere vincular iguales o desiguales efectos jurídicos, sino también a determinar las características que han de ser comparadas y a delimitar, hasta la frontera de lo arbitrario, el ámbito de las diferencias. Esta frontera de la arbitrariedad es permeable hasta un cierto punto: sólo cuando las decisiones legislativas llegan a un nivel de irracionalidad evidente, se consideran inconstitucionales.

Desde otra perspectiva, de la que se hace eco Pestalozza ${ }^{37}$, el hecho de que la violación del principio de igualdad (en la traducción literal, habría que hablar de la "desfavorabilidad contraria a la igualdad": "die Gleichheitswidrigkeit") dimane de una norma o de un complejo normativo ("einer Norm oder einem Normenkomplex"), esto es, si resulta de una interpretación aislada o de una interpretación sistemática, no es algo relevante para el BVerfG. Se ha de dar el mismo trato a los dos grupos ("beide Gruppen gleich zu behandeln" $)^{38}$.

Quizá convenga añadir, aunque sea una cuestión marginal a la que ahora nos ocupa, que en el caso de una "exclusión arbitraria de beneficio" contraria al principio de igualdad, es perfectamente posible no sólo declarar la inconstitucionalidad de la omisión, sino también la nulidad del texto. De hecho, como constata entre otros muchos Béguin ${ }^{39}$, en los primeros años de su actividad, el BVerfG utilizó con frecuencia los conceptos de inconstitucionalidad (verfassungswidrig) y nulidad (nichtig) poco más o menos como sinónimos, bien que a partir de 1958, en el contencioso del control normativo, el Tribunal haya pasado a seguir una práctica jurisprudencial inversa. No ha de extrañar este cambio de orientación jurisprudencial, y menos aún en relación a la "exclusión arbitraria de beneficio", pues si, por un lado, la declaración de inconstitucionalidad podría colisionar en mayor o menor medida, según los casos, con la ya en varias ocasiones mencionada libertad de configuración del legislador ("Gestaltungsfreiheit des Gesetzgebers"), por otro, como afirma Pestalozza, "die Nichtigerklärung beseitige nämlich zugleich die Anspruchsgrundlage für eine Begünstigung "40 (la declaración de nulidad elimina al mismo tiempo que el trato preferente el fundamento de la pretensión), lo que, como parece obvio, resulta no sólo paradójico, sino también por entero incongruente.

37 Christian PestalozZa: «Noch Verfassungsmässige" und "bloss Verfassungswidrige" Rechtslagen" (Zur Feststellung und kooperativen Beseitigung verfassungsimperfekter Zustände), en Bundesverfassungsgericht und Grundgesetz, herausgegeben von Christian STARCK, Erster Band (primer volumen), op. cit., págs. 519 y ss.; en concreto, pág. 531.

38 En cualquier caso, en los supuestos de omisión parcial ("Teilunterlassen"), el propio Pestalozza, en otro lugar, precisa que la laguna ("die Lücke") se examinará como parte de la norma ("als "Teil" der Norm") y no como algo aislado. Christian Pestalozza: Verfassungsprozeßrecht (Die Verfassungsgerichtsbarkeit des Bundes und der Länder), 3., völlig neubearbeitete Auflage, C.H. Beck'sche Verlagsbuchhandlung, München, 1991, pág. 125.

39 Jean-Claude BéGuin: Le contrôle de la constitutionnalité des lois en République Fédérale d'Allemagne, Economica, Paris, 1982, págs. 232-233.

40 Christian Pestalozza: "Noch Verfassungsmässige" und "bloss Verfassungswidrige" Rechtslagen", op. cit., pág. 531. 
Dicho lo que antecede, se ha de precisar que no debe pensarse en que siempre y en todo caso la exclusión de beneficio vulneradora del principio de igualdad ha de resolverse a través de la ampliación del beneficio al grupo o conjunto de individuos que han sido arbitrariamente privados del mismo. A este respecto, Ipsen, analizando el dilema entre la "declaración de nulidad" (Nichtigerklärung) y la "declaración de inconstitucionalidad" (Verfassungswidrigerklärung) ${ }^{41}$, aduce que las consecuencias financieras ("die finanziellen Folgen") de una resolución son difícilmente valorables ("schwer abschätzbar sind"), por lo que deben entrar en el terreno de la posible suspensión de la aplicación de la norma, de una especie de "paralización jurídica" ("Rechtsstillstand"). De esta forma, el legislador conserva la posibilidad de establecer nuevamente la disposición y puede volver a decidir acerca de si modifica o fija condiciones distintas para las prestaciones u otras ventajas ${ }^{42}$. Ipsen califica a continuación tal inaplicación de "paralización jurídica por razón de Estado" ("Rechtsstillstand aus Staatsräson"), descartando como base jurídica de la misma el art. 32 BVerfGG (al que aludimos precedentemente, y del que tan sólo recordaremos que contempla la posibilidad de adopción de medidas provisionales de naturaleza cautelar), pues para Ipsen, este bloqueo o suspensión de la aplicación de la norma se ha de considerar no como una precaución para casos excepcionales ("als Vorkehrung für Ausnahmefälle»), sino como una consecuencia jurídica regular ("als regelmäßige Rechtsfolge") de la declaración de inconstitucionalidad.

En definitiva, la "exclusión arbitraria de beneficio" no sólo ha supuesto una fuente inagotable de oportunidades de control de las omisiones (relativas) del legislador, sino que ha planteado al Tribunal Constitucional Federal problemas jurídicos (y no jurídicos) de la mayor trascendencia, que han propiciado una compleja casuística y han incentivado la creación por el juez constitucional de técnicas decisorias, técnicas a las que pasamos a referirnos a continuación.

\section{LA PLURALIDAD DE TÉCNICAS DECISORIAS DEL «BVerfG»}

En varias oportunidades nos hemos referido al más que notable instrumental decisorio del BVerfG, que se manifiesta en la pluralidad de variantes de sus sentencias, con las que pretende, y esto es importante subrayarlo, modificar determinados efectos jurídicos de las mismas desde una óptica de justicia material y funcional ${ }^{43}$. En el fondo de todo ello, la doctrina converge en una consideración común. Y así, Rupp-v. Brünneck aduce que la institucionalización

41 Jörn IPSEN: “Nichtigerklärung oder "Verfassungswidrigerklärung» — Zum Dilemma der verfassungsgerichtlichen Normenkontrollpraxis", en Juristenzeitung (JZ), 38. Jahrgang, Nr. 2, 21. Januar 1983, págs. 41 y ss.

42 Ibidem, pág. 44 pág. 58

43 Hans-Peter SchneIDER: "Jurisdicción constitucional y separación de poderes", op. cit., 
del Tribunal Constitucional Federal, como órgano constitucional independiente que es, no puede tener el sentido de que se confían sus tareas a un gremio que se mueve lejos de la política normal, pues sus sentencias no se limitan a ofrecer ideales teóricos constitucionales ("theoretischen Verfassungsidealen"), sin tener en cuenta los posibles efectos de las mismas ("ohne Rücksicht auf die möglichen Wirkungen seines Urteils"): fiat iustitia, pereat mundus ${ }^{\mu 4}$.

Conviene poner de relieve a este respecto el enorme cambio que en este punto entraña el BVerfG respecto al Reichsgericht. El Tribunal Supremo del Reich alemán sostenía la opinión de que poseía el derecho de resolver sin atender a las consecuencias prácticas de sus fallos ${ }^{45}$. Frente a ello, la jurisprudencia del BVerfG toma en cuenta los efectos reales, esto es, políticos, que pueden desencadenar sus sentencias. Como dice Krüger, es difícil imaginar que, según el sano criterio de la jurisdicción constitucional, se pueda disponer de la posibilidad de condenar al Estado a su ruina en nombre del Derecho ${ }^{46}$. Por lo demás, como en un artículo con el sugestivo título interrogativo de "Götterdämmerung?" (¿El crepúsculo de los dioses?) aduce Großfeld ${ }^{47}$, el BVerfG no debe de cambiar el ordenamiento estatal federal y, sobre todo, en lo que ahora importa, tampoco puede convertirse en un "puntiagudo crítico jurídico-constitucional ${ }^{48}$. En definitiva, con la jurisprudencia sentada al hilo de las notables sentencias que pueden reconducirse al ámbito del control omisivo, muy plural por lo demás, el Tribunal Constitucional Federal pone de relieve, con particular nitidez, que un órgano de esta naturaleza debe tener muy presentes las consecuencias políticas de sus fallos ${ }^{49}$, y es por ello por lo que no puede soslayar los graves efectos que el mismo vacío jurídico, o aún el caos jurídico, que pueden anudarse al juego combinado del binomio inconstitucionalidad/nulidad, pueden desencadenar en la vida social.

A todo ello hay que añadir que este esfuerzo dogmático del BVerfG se ha hecho particularmente necesario en el caso de las sentencias declaratorias de la inconstitucionalidad omisiva, al partir el Tribunal de la consideración de que es difícil declarar nulo un vacío jurídico, tesis de la que se haría eco quien fuera uno de sus presidentes, Wolfgang Zeidler ${ }^{50}$, argumento objeto de

44 Wiltraut RuPP-v. BRÜNNECK: "Darf das Bundesverfassungsgericht an den Gesetzgeber Appellieren?", en Festschrift für Gebhard Müller (Zum 70. Geburtstag des Präsidenten des Bundesverfassungsgerichts), Herausgegeben von Theo RitTersPach und Willi Geiger, J. C. B. Mohr (Paul Siebeck), Tübingen, 1970, págs. 355 y ss.; en concreto, págs. 364-365.

45 Herbert KRÜGER: Allgemeine Staatslehre, Kohlhammer Verlag, Stuttgart/Berlin/Köln/ Mainz, 1966, pág. 620.

46 Ibidem, pág. 620.

47 Bernhard GROßFELD: “Götterdämmerung? Zur Stellung des Bundesverfassungsgerichts", en Neue Juristische Wochenschrift (NJW), 48. Jahrgang, 1995, 2. Halbband, págs. 1719 y ss.

48 Ibidem, pág. 1723.

49 Klaus SCHLAICH: "El Tribunal Constitucional Federal Alemán", en la obra colectiva, Tribunales Constitucionales y Derechos Fundamentales, Centro de Estudios Constitucionales, Madrid, 1984, págs. 133 y ss.; en concreto, pág. 201.

50 Wolfgang ZEIDLER: "Cour constitutionnelle fédérale allemande" (Rapport. 7éme Conférence des Cours constitutionnelles européennes), en Annuaire International de Justice constitutionnelle, III, 1987, págs. 37 y ss.; en concreto, pág. 48. 
alguna crítica por parte de la doctrina italiana, cual sería, por ejemplo, el caso de D'Orazio ${ }^{51}$, quien lo tildaría de "pregiudiziale", contraponiéndolo a la superación del obstáculo realizada por la Corte costituzionale, que ha reconstruido de modo diferente la relación entre disposición, norma y omisión.

En definitiva, la gama de técnicas decisorias del Tribunal Constitucional Federal es notablemente amplia, tanto que algún autor ha llegado a escribir ${ }^{52}$ que en ningún otro sistema de control jurisdiccional normativo, sea difuso o concentrado, se puede constatar la utilización de tan amplia variedad de técnicas, aunque, el Verfassungsgerichtshof austriaco quizá tiene un aún mayor margen de discrecionalidad a la hora de disponer sobre los efectos jurídicos de sus sentencias ${ }^{53}$.

Por nuestra parte, vamos a circunscribir la exposición a los dos tipos de pronunciamientos que mayor relación guardan con el problema de la fiscalización de las omisiones legislativas: las apelaciones al legislador (Appellentscheidung) y las declaraciones de mera inconstitucionalidad o, si se prefiere, de inconstitucionalidad sin nulidad (Unvereinbarkeitserklärung). Haremos asimismo una breve alusión a las decisiones de interpretación conforme a la Constitución (Verfassungskonforme Auslegung) por cuanto que, contra lo que pudiera pensarse, el BVerfG también se vale de esta técnica para hacer frente a las omisiones, habiéndose puesto estos casos como ejemplo de una "Optimización constitucional" ("verfassungsrechtliche Optimierung") que posibilita una "construcción" de conformidad con la Constitución, mediante la analogía, reducción o derivación de premisas normativas constantes de la propia Constitución ${ }^{54}$.

\section{LAS DECISIONES DE APELACIÓN AL LEGISLADOR ("APPELLENTSCHEIDUNG")}

I. Fue la bien conocida Jueza del BVerfG Wiltraut Rup-v. Brünneck quien acuñó por primera vez la expresión Appell-Entscheidungen, en un no menos famoso artículo publicado en 1970, en el que se interrogaba acerca de si el BVerfG podía apelar al legislador. En la introducción de su escrito, Rupp-v. Brünneck aducía ${ }^{55}$ que en los casi veinte años de jurisprudencia del Tribunal

51 Giustino D'Orazıo: "Le sentenze costituzionali additive tra esaltazione e contestazione", en Rivista trimestrale di Diritto pubblico, 1992, fasc. 1, págs. 61 y ss.; en concreto, pág. 101.

52 Gilmar FERREIRA MENDES: “O apelo ao legislador (Appellentscheidung) na práxis da Corte Constitucional Federal Alemã", op. cit., pág. 270.

53 Puede verse al efecto el trabajo del profesor de la Universidad de Linz, Peter OBERNDORFER: "Die Verfassungsrechtsprechung im Rahmen der staatlichen Funktionen (Arten, Inhalt und Wirkungen der Entscheidungen über die Verfassungsmäigkeit von Rechtsnormen)", en Europäische Grundrechte Zeitschrift, 15. Jahrgang, Heft 8/9, 6. Mai 1988, págs. 193 y ss.

54 Christoph Gusy: Parlamentarischer Gesetzgeber und Bundesverfassungsgericht, Berlin, 1985, pág. 214. Cit. por Gilmar Ferreira Mendes: Jurisdição Constitucional, op. cit., pág. 288.

55 Wiltraut RuPP-v. BRÜNNECK: "Darf das Bundesverfassungsgericht an den Gesetzgeber Appellieren?", op. cit., pág. 355. 


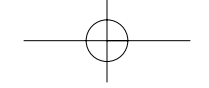

había algunas significativas resoluciones ("einige bedeutsame Entscheidungen") en las que aunque se daban aún ("noch") por constitucionales ciertas leyes, tras el control en sede constitucional daban, sin embargo, lugar a su derogación ("Aufhebung") por el propio legislador, en cuanto que tales resoluciones dejaban entrever sólidas dudas ("massive Bedenken") en contra de la constitucionalidad de la ley ("gegen die Verfassungsmäßigkeit des Gesetzes"). En algunos casos se llegó incluso a predecir que la ley sería declarada nula a causa de su inconstitucionalidad en un determinado momento futuro ("zu einem bestimmten zukünftigen Zeitpunkt").

La Jueza Rupp-v. Brünneck se planteaba en otro momento el sentido de este tipo de resoluciones dictadas en sede constitucional. A su juicio, con ellas se trataba de facilitar la legislación de los órganos constitucionales interesados, a la par que se trataba de dar claridad ("Klarheit") a los ciudadanos afectados ("dem betroffenen Bürger") sobre las posibilidades y límites admisibles jurídico-constitucionalmente de una determinada regulación. De esta manera, se daba validez igualmente a las apelaciones al legislador ("so gilt das gleiche für die Appelle an den Gesetzgeber"). Con tales resoluciones se pretende asimismo indicar una discrepancia ("eine Diskrepanz") entre las exigencias constitucionales ("den Anforderungen der Vefassung") y el simple Derecho ("dem einfachen Recht"), discrepancias cuya eliminación ("Beseitigung") queda en manos del legislador ${ }^{56}$.

Con base, entre otros, en los argumentos precedentes, la Jueza Rupp-v. Brünneck considerará injustificado ("unbegründet") el reproche ("der Vorwurf "), realizado por algunos frente a estas sentencias, de que las mismas entrañaban "una inadmisible intrusión en la competencia del legislador" ("eines unzulässigen Übergriffes in dem Funktions bereich des Gesetzgebers"), entendiendo, por el contrario, que "sind die Appell-Entscheidungen geradezu eine Bestätigung des vom Bundesverfassungsgericht geübten judicial self-restraint ${ }^{57}$ (las sentencias de apelación son realmente una confirmación de la experimentada judicial self-restraint del Tribunal Constitucional Federal). En definitiva, no sólo no suponen una intrusión atentatoria contra la discrecionalidad del legislador, sino que, bien al contrario, son una manifestación del self-restraint del juez constitucional, particularmente, en su relación con el poder legislativo.

Como puede apreciarse, la defensa por la Jueza Rupp-v. Brünneck de este tipo de decisiones constitucionales es realmente cerrada. En otro lugar de su trabajo ${ }^{58}$, se referirá de modo específico a la legitimidad de los puntos de vista pragmáticos («Legitimität des pragmatischen Standpunktes») que el BVerfG ha adoptado en las sentencias de apelación. 
En la doctrina alemana no han faltado, sin embargo, opiniones contrarias a este tipo de decisiones. Recordaremos, por ejemplo, la crítica de Klein ${ }^{59}$, para quien el llamamiento al legislador ("der Aufruf an den Gesetzgeber") se encuentra, por un doble motivo, con unos puntos de apoyo débiles («auf schwachen Füen"): el BVerfG no puede pronosticar el momento exacto del cambio de la norma a la inconstitucionalidad ("den genauen Zeitpunkt des Umschlags der Norm in die Verfassungswidrigkeit"), pero, sobre todo, la apelación que formula el Tribunal Constitucional Federal no da ningún argumento jurídico («keine Rechtsgrundlage»).

Se ha señalado asimismo que la apelación al legislador expresa un intento de compensar, mediante una decisión judicial, el déficit que se ha identificado en el proceso de decisión parlamentaria ${ }^{60}$, lo que parece aducirse con una perspectiva indiscutiblemente crítica. Y Bachof, tras aludir (alusión que ha de entenderse hecha, aunque no se precise el destinatario concreto de la misma, al Tribunal Constitucional Federal) a cómo los Tribunales Constitucionales han prescindido frecuentemente de declarar nulas las leyes contrarias a la Constitución, aduce que, a su juicio, así debieran de haberlo hecho, calificando las construcciones jurídicas que estamos analizando de "construcciones frecuentemente poco convincentes". En específica alusión a la Ley del Tribunal Constitucional Federal (BVerfGG), Bachof añade que tales decisiones eran difíciles de conciliar con el texto entonces vigente de la mencionada ley, puesto que ésta preceptuaba en forma unívoca que una ley contraria a la Constitución debía ser declarada nula ${ }^{61}$. El Tribunal, — constata finalmente el profesor de Tübingen - no obstante la expuesta contradicción con el texto legal, se consideró facultado para denegar la consecuencia de la nulidad a una mera declaración de inconstitucionalidad. Sin embargo, y ello es bien significativo, estas decisiones en las que el BVerfG se arrogó el derecho de corregir al legislador, apenas fueron criticadas.

El argumento de que este peculiar tipo de decisiones constitucionales no entra dentro de las competencias del Tribunal, que tan bien ejemplifica la afirmación de Klein de que "Futurologie gehört nicht zu den Aufgaben des Gerichts ${ }^{62}$ (la futurología no entra dentro de las competencias de los tribunales),

59 Eckart KLEIN: "Verfassungsprozeßrecht — Versuch einer Systematik an Hand der Rechtsprechung des Bundesverfassungsgerichts", en Archiv des öffentlichen Rechts (AöR), 108. Band, Heft 3, September 1983, págs. 410 y ss.; en concreto, pág. 434.

60 Brun-Otto Bryde: Verfassungsentwicklung, Stabilität und Dynamik im Verfassungsrecht der Bundesrepublik Deutschland, Nomos, Baden-Baden, 1982, págs. 397-398. Cit. por Gilmar FERREIRA MENDES: Jurisdição Constitucional, op. cit., pág. 305.

61 Otto BACHOF: "Nuevas reflexiones sobre la jurisdicción constitucional entre Derecho y política", en Boletín Mexicano de Derecho Comparado, año XIX, n. ${ }^{\circ}$ 57, Septiembre/Diciembre 1986, págs. 837 y ss.; en concreto, págs. 847-848. Ciertamente, las reflexiones de Bachof tienen como punto de referencia más las decisiones que analizaremos con posterioridad que las ahora contempladas, pero aludimos a ellas ahora porque, en realidad, encierran una reflexión crítica generalizada respecto de las sentencias que estamos analizando.

62 Eckart KLEIN: "Verfassungsprozeßrecht - Versuch einer Systematik an Hand der Rechtsprechung des Bundesverfassungsgerichts", op. cit., pág. 434. 
ha de ser relativizado si se piensa que este tipo de sentencias, en realidad, conforman una peculiar modalidad de decisiones desestimatorias, de rechazo de la inconstitucionalidad aducida por el recurrente, por lo que no requieren de modo inexcusable de una fundamentación o soporte legal diferente a aquel en el que se sustentan tales decisiones desestimatorias. Schlaich y Korioth se manifiestan con claridad meridiana al respecto cuando, refiriéndose a las llamadas decisiones "aún constitucionales", afirman: "Die Entscheidungsvariante des "noch verfassungsmäßige" mit Appell ist ein Sonderfall der Vereinbarkeitserklärung, ${ }^{63}$ (la variante de las decisiones "aún constitucional" con apelación es un caso especial de una declaración de compatibilidad). Pero además, hay algunos otros argumentos a los que se refiriera Zeidler ${ }^{64}$, que nos parecen lo suficientemente convincentes como para hacernos eco de ellos. Quien fuera "Präsident des Bundesverfassungsgerichts" aludiría a: la necesidad de evitar el vacío jurídico o incluso la anarquía jurídica resultante de la declaración de nulidad de un texto legal; el respeto al margen de maniobra reservado al legislador, que desempeña un rol más que notable para el BVerfG, y el hecho de que no entra en las atribuciones del Tribunal tomar decisiones normativas cuando el legislador ha descuidado regular a través de la ley un determinado ámbito jurídico o ha rehusado conceder a un grupo una prestación que, por el contrario, otorga a otro.

En fin, hay otro argumento más técnico al que se refiere Pestalozza ${ }^{65}$, que es perfectamente válido. Entre la nulidad y la constitucionalidad sin tacha ("Zwischen Nichtigkeit und makelloser Verfassungsmäßigkeit) parece desarrollarse una zona gris ("eine graue Zone") de situaciones de imperfección constitucional ("verfassungsimperfekter Zustände"), en la que se puede diferenciar, desde puntos de vista objetivos ("sachlichen Gesichtspunkten"), lo que está prohibido de lo que simplemente no está de por sí permitido. Y es que, en último término, según el profesor de la "Freien Universität Berlin", situaciones jurídicas "aún constitucionales" (Noch verfassungsmäßige") son aquellas que se encuentran en el camino hacia la inconstitucionalidad ("auf dem Weg zur Verfassungswidrigkeit"), pero que aún no la han alcanzado completamente ("sie aber noch nicht vollends erreicht haben") ${ }^{66}$. Esta argumentación, es obvio, viene dirigida tan sólo hacia una de las situaciones desencadenantes de las decisiones de apelación al legislador, que, por otra parte, no es en modo alguno la que en mayor medida interesa al objeto de nuestro estudio, pero, con todo, es un argumento que nos parece perfectamente válido, a añadir a los ya precedentemente expuestos en favor de la legitimidad de esta técnica decisoria, cuya adopción por el Tribunal Constitucional Federal nos parece muy afortunada.

63 Klaus SCHLAich y Stefan Korioth: Das Bundesverfassungsgericht. Stellung, Verfahren, Entscheidungen, 5., neubearbeitete Auflage, Verlag C.H. Beck, München, 2001, pág. 290.

64 Wolfgang ZeIdLER: "Cour constitutionnelle fédérale allemande", op. cit., págs. 43-44

65 Christian PestalozZA: "Noch verfassungsmäßige" und "bloss verfassungswidrige" Rechtslagen", op. cit., pág. 540.

66 Ibidem, pág. 540. 
Cuanto hasta aquí se ha expuesto, creemos que deja claro, por lo menos de modo implícito, algo a lo que ya hemos aludido: la pluralidad de tipos de decisiones de apelación al legislador que pueden ubicarse bajo el genérico rótulo de Appellentscheidungen. Schulte ha llegado incluso a esbozar una tipología bajo el enunciado general de "Fallgruppen von Appellentscheidungen" ${ }^{67}$ (grupos de casos de decisiones de apelación). Este tipo de decisiones emerge en la jurisprudencia del BVerfG en una constelación de casos diferentes («unterschiedlichen Fallkonstellationen"). Con frecuencia, señala el mencionado autor, la argumentación del Tribunal viene caracterizada por las particularidades de estos casos especiales y poco consistentes ("wenig konsistent"). Es por lo mismo por lo que Schulte entiende que las Appellentscheidungen sólo admiten una sistematización relativa, no obstante lo cual, nuestro autor separa tres casos de grupos típicos ("drei typische Fallgruppen") ${ }^{68}: 1$ ) Appellentscheidungen con motivo de cambios en la realidad o en la interpretación constitucional («eines Wandels der Realität oder der Verfassungsinterpretation"); 2) Appellentscheidungen con motivo de un mandato al legislador (un encargo a la legislación, en la traducción literal: "aus Anlaß unerfüllter Gesetzgebungsaufträge»), y 3) Appellentscheidungen con motivo de la falta de evidencia de una vulneración constitucional ("aus Anlaß fehlender Evidenz des Verfassungsverstoses").

II. Se admite de modo generalizado que la decisión dictada el 4 de mayo de 1954 sobre el Estatuto del Sarre constituye el punto de partida de este tipo de decisiones de apelación. En dicho caso se resolvió que las disposiciones legislativas adoptadas con el ánimo de superar el «estatuto de ocupación" de ese territorio, aunque fuesen incompletas, coadyuvaban a una gradual compatibilización de la situación jurídica con la Grundgesetz y, por lo mismo, debían ser consideradas "aún constitucionales". En último término, se trataba de una típica "situación de hecho".

En otra decisión muy próxima en el tiempo a la anterior, la de 4 de abril de 1955, relativa a la constitucionalidad de la ley federal de 23 de octubre de 1954, por la que se aprobaba el Estatuto sobre el Sarre (Saarstatut), relacionada asimismo con la aplicación del "estatuto de ocupación", el BVerfG formulaba su conocida "teoría de la aproximación", que podía quedar compendiada en las siguientes reflexiones: "Se desecha la declaración de inconstitucionalidad porque la situación creada por el Tratado está más próxima a la establecida por la Ley Fundamental de lo que lo estaba la anteriormente en vigor. Si se pretendiese una disciplina plenamente compatible con la Ley Fundamental se estaría consagrando un rigor constitucional que podría resumirse en la siguiente fórmula: la situación mala debe subsistir si la mejor no puede ser alcanzada. Tal orientación no se corresponde a la voluntad de la Ley Fundamental ${ }^{69}$.

67 Martin Schulte: "Appellentscheidungen des Bundesverfassungsgerichts", en Deutsches Verwaltungs Blatt (DVBl), 103. Jahrgang, 15. Dezember 1988, págs. 1200 y ss.; en concreto, págs. 1201-1202.

68 Ibidem, pág. 1201.

69 Cfr. al respecto, Gilmar FerReIRA MENDES: “O apelo ao legislador...”, op. cit., págs. 289-290. 
En la primera categoría de decisiones de apelación a que se refería Schulte, propiciada por cambios en la realidad o en la interpretación constitucional, suele ubicarse la también muy conocida sentencia de 22 de mayo de 1963, relativa a la división de los distritos electorales, en donde la apelación al legislador iba a ser la consecuencia de un cambio en la situación de hecho, resultante de una sensible alteración de la estructura demográfica en los distintos entes territoriales de la República Federal. Esa alteración conducía inexcusablemente a que la división de los distritos electorales realizada en 1949, mantenida de modo incólume hasta entonces, vulnerara las exigencias dimanantes del principio de igualdad electoral consagrado por el art. 38.1 ${ }^{\circ}$ GG. El Tribunal Constitucional se abstuvo, sin embargo, de declarar la inconstitucionalidad con fundamento en que la situación de quiebra del principio de igualdad no podía ser constatada en el momento de la promulgación de la ley (septiembre de 1961), no obstante lo cual instaba al legislador a que adoptase las medidas necesarias para la modificación de los distritos electorales con la finalidad de aminorar la divergencia existente hasta tramos aceptables. Este caso presentaba unas connotaciones en verdad peculiares. Si el BVerfG hubiese declarado la inconstitucionalidad de la ley que regulaba los distritos electorales, la consecuencia habría sido la invalidez de las últimas elecciones parlamentarias y, consecuentemente, la ilegitimidad del Parlamento y del propio Gobierno. En tal caso, no habría existido ningún órgano con legitimidad para promulgar una nueva ley electoral una vez que había finalizado el mandato del anterior Parlamento y la previsión constitucional del art. 81 GG sobre el estado de necesidad legislativa ("des Gesetzgebungsnotstand erklären") no era de aplicación al caso en cuestión.

La decisión de los distritos electorales es también reconducible al tercero de los tipos de Appellentscheidungen diferenciados por Schulte, esto es, el supuesto de falta de evidencia de una violación constitucional, pues en el momento de promulgarse la Ley de 17 de septiembre de 1961, la inconstitucionalidad no era identificable con tanta claridad como para poder invalidar la división territorial electoral fijada por la ley. De ahí que el Tribunal, en tales casos, exhorte al legislador a que corrija la situación "noch Verfassungsmäßige» (aún constitucional).

Algo similar puede decirse respecto de la sentencia relativa a la ley de pensiones, que no obstante contravenir el principio de igualdad o, si así se prefiere, el de paridad de tratamiento entre hombres y mujeres del art. 3. ${ }^{\circ} .2 \mathrm{GG}$, vio confirmada transitoriamente su aplicación ${ }^{70}$. A juicio de

70 "No se puede decir en la actualidad — razonaba el BVerfG - que las más rigurosas condiciones que establece la legislación vigente para la pensión de un viudo en comparación con las exigencias para ser acreedor a una pensión de este tipo por una viuda en la Seguridad Social sean incompatibles con la Grundgesetz. El legislador debe, sin embargo, esforzarse por encontrar una solución apropiada que excluya en el futuro una violación del art. 3, apartados 2 y 3 de la Ley Fundamental». Cit. Por Klaus SCHLAICH: "El Tribunal Constitucional Federal Alemán”, op. cit., págs. 200-201. 
Schlaich ${ }^{71}$, esta solución se inspiraba en último término en el principio de preferencia de la interpretación conforme a la Constitución (Verfassungskonforme Auslegung) de una norma y en el de presunción de la validez de una ley.

En todo caso, con este tipo de decisiones, como bien señalara Schulte ${ }^{72}$, el Tribunal Constitucional dejaba claro, en el marco de sus razonamientos y posibilidades decisorias, cuán defectuosa era una regulación jurídica ("wie mängelbehaftet eine gesetzliche Regelung ist") y cómo urgía por ello mismo una intervención del legislador ("eines Eingreifens des Gesetzgebers"). Con su apelación, dirán por su parte Schlaich y Korioth ${ }^{73}$, el Tribunal insta al legislador para que establezca unas plenas condiciones de constitucionalidad ("einen voll verfassungsmäßigen Zustand") o para soslayar en el futuro una inminente inconstitucionalidad ("oder eine in der Zukunft drohende Verfassungswidrigkeit abzuwenden").

III. El aviso ${ }^{74}$ de una futura inconstitucionalidad («die Ankündigung kunftiger Verfassungswidrigkeit"), como bien señala Pestalozza ${ }^{75}$, no obliga jurídicamente a actuar al legislador, pero convierte en errónea su permanente inactividad ("aber sie setzt seine anhaltende Untätigkeit ins Unrecht"). Esta circunstancia se acentúa si se piensa que, en ocasiones, el BVerfG ha fijado un período de tiempo ("Fristsetzung") dentro del cual el legislador había de adecuar a la Constitución la disciplina normativa de que se tratara.

Los efectos de estas decisiones no se hallan contemplados por el ordenamiento jurídico. La praxis revela que en la parte dispositiva de tales decisiones el BVerfG se limita tan sólo a reconocer la constitucionalidad del texto legal del que está conociendo, siendo en la fundamentación jurídica de la sentencia en donde el juez constitucional acoge la apelación al legislador, con lo que ello puede entrañar de un mayor o menor número de indicaciones sobre las reglamentaciones a llevar a cabo en un futuro más o menos indeterminado. Más recientemente, el BVerfG ha pasado a incluir en la parte dispositiva de la sentencia una suerte de advertencia, al señalar que la constitucionalidad de la ley se ha de entender "conforme a los fundamentos de la decisión" ("nach Maßgabe der Gründe").

71 Klaus SCHLAICH: "Corte costituzionale e controllo sulle norme nella Repubblica Federale di Germania", en Quaderni Costituzionali, anno II, n. ${ }^{\circ}$ 3, Dicembre 1982, págs. 557 y ss.; en concreto, pág. 576 . 1206.

72 Martin Schulte: "Appellentscheidungen des Bundesverfassungsgerichts", op. cit., pág.

73 Klaus Schlaich y Stefan Korioth: Das Bundesverfassungsgericht. Stellung, Verfahren, Entscheidungen, op. cit., pág. 290.

74 Precisamente, Schneider tilda estas decisiones dictadas en sede constitucional de "resoluciones de aviso" (Warn — oder Signalentscheidung"), diferenciándolas de la "resolución de recomendación" (Appellentscheidung). Hans-Peter SCHNEIDER: "Jurisdicción constitucional y separación de poderes", op. cit., pág. 59.

75 Christian PestalozZa: "Noch verfassungsmäßige" und "bloss verfassungswidrigem, op. cit., pág. 556 
Por otro lado, las hipotéticas afirmaciones de este tipo de decisiones en torno a una posible inconstitucionalidad de la ley, no se hallan cubiertas por el efecto de cosa juzgada (Rechtskraft) ${ }^{76}$, ni tampoco quedan dotadas de la fuerza de ley (Gesetzkraft) por cuanto es obvio que el desarrollo posterior que haya de sufrir el texto legal en cuestión no es objeto de fiscalización.

A la vista de lo que se acaba de señalar, parece claro que las alusiones a los fundamentos jurídicos de la decisión que últimamente se hacen en la parte dispositiva persiguen evitar que, de resultas de la declaración de constitucionalidad, la ley quede exenta de críticas. Se trata, bien al contrario, de sentar las bases para posibilitar que, después de transcurrido un cierto plazo, pueda suscitarse la cuestión de la posible inconstitucionalidad de la ley. Se ha llegado incluso a decir, que en los fundamentos de estas decisiones, lejos de establecerse una presunción irrefragable de constitucionalidad, el juez constitucional establece una "presunción de inconstitucionalidad para el futuro" ${ }^{77}$. Desde esta óptica, es bastante evidente que la apelación al legislador verificada en los fundamentos jurídicos se halla bien alejada de poder ser considerada como un mero obiter dictum. Piénsese además que en no pocas ocasiones el BVerfG va más allá de una mera apelación al legislador, pronunciándose de modo imperativo sobre la situación que ha de subsistir tras su decisión. Buen ejemplo de ello lo podemos encontrar en estas dos circunstancias: en ocasiones, el Tribunal Constitucional Federal ha reconocido a los tribunales ordinarios la facultad de otorgar plena eficacia a las disposiciones constitucionales a través del proceso de su concreción (Konkretisierung); en otras oportunidades, el Tribunal ha previsto taxativamente un plazo para que el legislador proceda a llevar a cabo su obra de mediación normativa. Ciertamente, el BVerfG no puede forzar al legislador a que proceda a llevar a cabo tal actuación de mediación normativa. Por lo mismo, ni tan siquiera la fijación de ese plazo puede entenderse en el sentido de imposición inexcusable de legislar. Pero resulta una obviedad que, transcurrido ese período de tiempo sin que el legislador lleve a cabo la actuación normadora a la que ha sido instado en sede constitucional, el Tribunal Constitucional, siempre, claro es, que sea requerido a ello, declarará la inconstitucionalidad del texto legal, pues es patente que a la inacción del legislador no se anuda el automático reconocimiento de la inconstitucionalidad de la ley. Por lo demás, la praxis revela que no es en modo alguno imposible que el Tribunal proceda a prorrogar el plazo que en un primer momento dio al poder legislativo. Ese plazo debe, por lo tanto, ser considerado tan solo como un plazo de carencia ("Karenzfrist") dentro del cual la

76 En igual sentido, Zeidler escribe que «les pures décisions d'appel au législateur n'ont aucune autorité directe de la chose jugée». Wolfgang ZEIDLER: "La Cour constitutionnelle fédérale allemande", op. cit., pág. 51.

77 Jean-Claude BéGuin: Le contrôle de la constitutionnalité des lois en République Fédérale d'Allemagne, op. cit., pág. 272. 
ley "aún constitucional» ("noch verfassungsmäßige») puede ser legítimamente aplicada $^{78}$.

Innecesario es decir que no entra en el ámbito competencial del BVerfG adoptar decisiones normativas en defecto de una actuación del legislador, si bien no puede ignorarse, aunque, en rigor, sea una cuestión no estrictamente relacionada con la que ahora nos ocupa, que al amparo del ya referido art. 35 BVerfGG, en ocasiones, el Tribunal ha procedido a dictar normas jurídicas transitorias con las que viabilizar la ejecución de sus sentencias. Una de las resoluciones relativas a la interrupción voluntaria del embarazo podría ser a estos efectos paradigmática. La cuestión no deja de ser problemática, como muestra el interrogante que al efecto se plantea Schlaich: ¿Puede un sistema jurídico basado en los principios de legalidad y seguridad jurídica soportar este modo de decisión de un Tribunal? ${ }^{79}$. Otros sectores de la doctrina han explicitado asimismo serias dudas acerca de si el BVerfG no ha usurpado las tareas propias del legislador. Tal es el caso de Zweigert, de cuya reflexión ya nos hicimos $\mathrm{eco}^{80}$. En igual dirección, Zeidler ha podido afirmar: "Han vaciado la copa (llena de competencias) hasta su fin. Y a veces se sirven sin ser preguntados $"{ }^{81}$. Tras ello, innecesario es decirlo, subyace la omnipresente problemática cuestión del judicial self-restraint del Tribunal Constitucional Federal $^{82}$.

La praxis nos muestra que el legislador ha seguido, sin manifestaciones significativas en contrario, las indicaciones del BVerfG, plasmadas, como ya se ha dicho, en los fundamentos jurídicos de estas decisiones. Como al efecto es-

78 Christoph MoEnch: Verfassungswidriges Gesetz und Normenkontrolle, Nomos, Baden-Baden, 1977, págs. 186-187. Cit. por Gilmar Ferreira Mendes: “O apelo ao legislador...”, op. cit., pág. 300.

79 Klaus Schlaich: “El Tribunal Constitucional Federal Alemán”, op. cit., págs. 208-209.

80 Konrad ZwEIGERT: "Einige rechtsvergleichende und kritische Bemerkungen zur Verfassungsgerichtsbarkeit", op. cit., pág. 74.

81 Karl ZeIDLER: "Zum Verwaltungsrecht und Verwaltung in der Bundesrepublik seit dem GrundgesetZ", en Der Staat, 1962, pág. 326. Cit. por Karl KoRINEK: “La Jurisdicción constitucional en el sistema de las funciones estatales", en Revista Uruguaya de Estudios Internacionales, año 3-4, n. ${ }^{\text {os }}$ 5/6/7/8/9, 1984-1985, págs. 49 y ss.; en concreto, pág. 62.

82 Cfr. al efecto, Martin KrielE: "Recht und Politik in der Verfassungsrechtsprechung. Zum Problem des judicial self-restraint", en Neue Juristische Wochenschrift (NJW), 29. Jahrgang, Heft 18, 5. Mai 1976, págs. 777 y ss. Para Kriele, todos los reparos contra la jurisprudencia constitucional ("Alle Einwände gegen die Verfassungsrechtsprechung") pueden agruparse bajo el lema ("unter dem Stichwort"): judicial self-restraint, todos se agrupan juntos en una demanda: "Im Verfassungsrecht nicht politisch, sondern juristischen zu urteilen" (en las sentencias jurídico-constitucionales, nada políticamente, sino jurídicamente" (p. 777). Y en sintonía con lo que se acaba de decir, la polémica presente en torno al tratamiento jurisprudencial de ciertas cuestiones de honda carga política. Benda, que fue presidente del BVerfG, haciendo una suerte de balance de las relaciones entre el juez constitucional y el legislador, en la tercera década de vigencia de la Grundgesetz, escribía: "Irritationen sind, zumal bei politisch umstrittenen Fragen unvermeidlich und sollten nicht überbewertet werden" (Las irritaciones están sobre todo junto a cuestiones inevitables políticamente controvertidas y no deben sobrevalorarse). Ernst BENDA: "Bundesverfassungsgericht und Gesetzgeber im dritten Jahrzehnt des Grundgesetzes", en Die Öffentliche Verwaltung (DÖV), 32. Jahrgang, Heft 13-14, Juli 1979, págs. 465 y ss.; en concreto, pág. 470. 
cribe Landfried ${ }^{83}$, "Members of Parliament perceive the binding efficacy to last forever and to include nearly every sentence of a decision. That is why an appeal to the Members of Parliament to have more "political self-confidence" is as important as an appeal to the judges to practise more ijudicial self-restraintm. Y Y desde una óptica igualmente pragmática, habría que añadir que el peculiar significado que los órganos estatales, y también la opinión pública, atribuyen a los pronunciamientos del Tribunal Constitucional Federal, aseguran a las Appellentscheidungen una eficacia comparable a la de cualquier otra decisión de naturaleza preceptiva ${ }^{84}$, lo que se corrobora a la vista de las, en ocasiones, profundas reformas legislativas a las que este tipo de decisiones han dado lugar. En análogo sentido, Béguin ha constatado ${ }^{85}$ que con la técnica del reenvío al legislador, surtido de directivas, el Tribunal se ha dotado de un instrumento de intervención eficaz, en cuanto que le permite impulsar la fase de decisión legislativa a cuyo través será restablecida una situación conforme a la Constitución en los más diferentes ámbitos del Derecho.

IV. Una última reflexión se impone en atención a la relación entre el legislador y el BVerfG. Se ha dicho ${ }^{86}$ que la actividad del BVerfG no está limitada a la comprobación de las lesiones constitucionales evidentes (eevidenter Verfassungsverletzungen"), pero que tampoco puede suponer una facultad para la definición de objetivos políticos independientes ("die Befugnis zu eigenständiger politischer Zielbestimmung") ${ }^{87}$. Y en la misma dirección, Simon $^{88}$ cree conveniente la no recomendación por el Tribunal de fórmulas alternativas en sustitución de una regulación inconstitucional, pues si bien tales recomendaciones, como ya se ha señalado, no son vinculantes, influyen indirectamente en el proceso político, al margen ya de que esas admoniciones son más fáciles de formular que de seguir. Entre los dos mojones fijados por Jekewitz debe delimitarse la actuación del BVerfG en este tipo de decisiones, lo que no siempre es fácil de conseguir y no ha dejado de suscitar apreciaciones harto críticas hacia el Tribunal, como ejemplifican paradigmáticamente

83 Christine LANDFRIED: "Constitutional Review and Legislation in the Federal Republic of Germany", en Christine LANDFried (Ed.), Constitutional Review and Legislation. An International Comparison, Nomos Verlagsgesellschaft, Baden-Baden, 1988, págs. 147 y ss.; en concreto, págs. 166-167.

84 En tal sentido, Gilmar Ferreira Mendes, en "O apelo ao legislador...", op. cit., pág. 301, quien sigue al efecto la opinión de Christine LANDFrIED, en Bundesverfassungsgericht und Gesetzgeber, Nomos, Baden-Baden, 1984, pág. 52.

85 Jean-Claude BéGuin: Le contrôle de la constitutionnalité des lois..., op. cit., pág. 293.

86 Jürgen JeKewITZ: “Bundesverfassungsgericht und Gesetzgeber ( $\mathrm{Zu}$ den Vorwirkungen von Existenz und Rechtsprechung des Bundesverfassungsgerichts in den Bereich der Gesetzgebung)", en Der Staat, 19. Band, 1980, págs. 535 y ss.; en concreto, pág. 542.

87 La función democrática del Tribunal —añade Jekewitz más adelante- se encuentra en sus resoluciones de autoridad sobre cuestiones jurídico-constitucionales dudosas ("in der autoritativen Entscheidung verfassungsrechtlicher Zweifelsfragen"). Jürgen JEKEWITZ: "Bundesverfassungsgericht und Gesetzgeber", op. cit., pág. 542.

88 Helmut Simon: "La Jurisdicción Constitucional", en Benda, Mainofer, Vogel, Hesse y HeYde: Manual de Derecho Constitucional, IVAP/Marcial Pons, Madrid, 1996, págs. 823 y ss.; en concreto, pág. 853. 
algunas reflexiones de Großfeld, quien se interroga ${ }^{89}$ acerca de si es poder público un Tribunal Constitucional Federal de competencia general ("ein allzuständiger BVerfG»), al margen de la separación de poderes ("außerhalb der Gewaltenteilung»), para añadir de inmediato que la confianza final ("das Letztvertrauen") reside en los tribunales ordinarios ("den ordentlichen Gerichten") de acuerdo con la tradición que ve en el Derecho civil ("Zivilrecht") el guardián más fiable de la libertad y de la igualdad ("den verläßlichen Hüter von Freiheit und Gleichheit»). Innecesario es decir que tan discutibilísima opinión encuentra réplicas de tanto peso específico como la de Hesse, para quien la jurisprudencia constitucional no se ha limitado a adecuar su interpretación de los derechos fundamentales a una realidad social cambiante ("einer veränderten sozialen Wirklichkeit»), sino que ella misma se ha convertido en motor de su desarrollo futuro ("zum Motor künftiger Entwicklung") ${ }^{90}$.

Las críticas doctrinales, creemos que más bien puntuales, hacia algunos aspectos de la actuación del BVerfG no deben obscurecer en lo más mínimo el extraordinario rol que la jurisprudencia constitucional del Tribunal ha jugado en relación a los derechos fundamentales. Bastaría con recordar la sentencia dictada en el caso Elfes, de 16 de enero de 1957, en la que se definirá el derecho al libre desarrollo de la personalidad ("Recht auf die freie Entfaltung seiner Persönlichkeit") del art. 2. .1 GG como "libertad general de acción", que, por lo mismo, ampara a todas las demás libertades, con independencia de que estén o no enumeradas en la Ley Fundamental, o la celebérrima Lüth Urteil, de 15 de enero de 1958, cuyo "redemptive style" sería puesto en contraste con "the United States Supreme Court's caution "91, y a la que se debe la definición de los derechos fundamentales como un sistema de valores que debe regir y definir la totalidad del sistema jurídico, para dejar meridianamente clara la relevancia de la función desempeñada por el BVerfG en relación a los Grundrechte, y ello no sólo en la República Federal, pues es bien conocido el notabilísimo impacto que su doctrina en materia de derechos ha tenido en otros órganos de la justicia constitucional europea. Y qué duda cabe de que a través de este peculiar tipo de sentencias que son las Appellentscheidungen, el Tribunal ha proyectado su jurisprudencia sobre el legislador, instándole a una actuación plenamente sensible hacia los derechos fundamentales y los grandes valores que subyacen en el ordenamiento constitucional alemán ${ }^{92}$. Sin ir más lejos, el caso

89 GROßFELD: "Götterdämmerung? Zur Stellung des Bundesverfassungsgerichts", en Neue Juristische Wochenschrift (NJW), 48. Jahrgang, 1995, 2. Halbband, págs. 1719 y ss.; en concreto, pág. 1721.

90 Konrad Hesse: "Verfassungsrechtsprechung im geschichtlichen Wandel", en Juristen Zeitung (JZ), 50. Jahrgang, 17. März 1995, págs. 265 y ss.; en concreto, pág. 267.

91 Bruce ACKERMAN: "The Rise of World Constitutionalism", en Virginia Law Review, vol. 83, 1997, págs. 771 y ss.; en concreto, pág. 796.

92 Como con toda razón aduce Ipsen, es exigible del legislador algo más que la voluntad de no actuar de forma inconstitucional ("den Willen nicht verfassungswidrig zu handeln"). Jörn IPSEN: "Nichtigerklärung oder "Verfassungswidrigerklärung»", op. cit., pág. 44. 
resuelto por la sentencia de 29 de enero de 1969, en un supuesto tan sensible como el de la igualdad de los hijos, con independencia de que se tengan dentro o fuera del matrimonio, ilustraría de este influjo del Tribunal sobre el legislador en materia de derechos fundamentales.

\section{LAS DECLARACIONES DE INCONSTITUCIONALIDAD SIN NULIDAD ("UNVEREINBARKEITSERKLÄRUNG»)}

I. En los primeros años de vida del Tribunal Constitucional Federal, éste vinculó los términos "inconstitucionalidad" (verfassungswidrig) y "nulidad" (nichtigkeit) a través prácticamente de una relación biunívoca, de tal modo que a la primera se anudaba la segunda. El binomio parecía inescindible. No ha de extrañar tal conexión si se atiende a la previsión del art. 78 BVerfGG, que dispone que si el Tribunal llegare a la convicción de que una disposición del ordenamiento federal es incompatible ("unvereinbar") con la Grundgesetz (o una disposición del ordenamiento de los Länder lo es con la Ley Fundamental o con otras disposiciones del Derecho federal) declarará nula la ley ("so erklärt es das Gesetz für nichtig»). La incompatibilidad con la Grundgesetz, esto es, la inconstitucionalidad, se traducía, pues, en la nulidad. La situación iba, sin embargo, a cambiar a partir de 1958, al declarar una ley inconstitucional sin anudarle la declaración de nulidad, quebrando de esta forma por primera vez el binomio inconstitucionalidad/nulidad. Con ello, el BVerfG creaba un tipo de decisiones que bien pueden ubicarse entre las sentencias estimatorias, que pronuncian la nulidad absoluta de las normas impugnadas, y las sentencias desestimatorias o de rechazo, que declaran la conformidad constitucional de las normas impugnadas ${ }^{93}$. Y ello es así por cuanto, como señala Pestalozza ${ }^{94}$, en este tipo de resoluciones constitucionales sólo puede reconocerse la infracción ("Hier kann nur der Verstoß festgestellt») y no se declarará la nulidad ("und nichts für nichtig erklärt werden»). En otro lugar, el propio autor, en alusión a la insconstitucionalidad de las omisiones del legislador, razonaba que parecía imposible declarar la nulidad de una omisión legislativa ("Es soll nun nicht möglich sein, das gesetzgeberische Unterlassen für nichtig zu erklären"); la decisión, añadía Pestalozza95, no puede sino limitarse a confirmar la inconstitucionalidad ("es bewendet bei der Feststellung der Verfassungswidrigkeit").

93 En sentido análogo, entre otros, Antonio CERvatr: "Tipi di sentenze e tipi di motivazioni nel giudizio incidentale di costituzionalità delle leggi", en la obra colectiva, Strumenti e tecniche di giudizio della Corte costituzionale (Atti del Convegno, Trieste 26-28 maggio 1986), Giuffrè, Milano, 1988, págs. 125 y ss.; en concreto, págs. 131-132.

94 Christian Pestalozza: Verfassungsprozeßrecht (Die Verfassungsgerichtsbarkeit des Bundes und der Länder), op. cit., pág. 340.

95 Christian PestalozZa: "Noch verfassungsmäßige" und "bloss verfassungswidrige" Rechtslagen", op. cit., pág. 526 
El punto de partida para el desarrollo de este tipo de decisiones fue la ya comentada "exclusión arbitraria de beneficio" (Willkürlicher Begünstigungsauschuss), incompatible con las exigencias del principio de igualdad, si bien la jurisprudencia del BVerfG no se iba a limitar a ese supuesto, extendiendo progresivamente esa modalidad de sentencias a otros casos en los que, por distintas circunstancias, el Tribunal entendió necesario declarar la mera incompatibilidad (Unvereinbarkeit) de la norma con la Ley Fundamental, pero sin anudarle la nulidad.

En 1970 (Ley de 21 de diciembre de 1970), la BVerfGG iba ser modificada al objeto de positivar lo que ya venía siendo una pauta consolidada del Tribunal. A tal efecto, se introdujo en el art. 31.2 una específica referencia a la declaración de mera incompatibilidad. El precepto en cuestión comienza aludiendo a los casos en que una resolución del Tribunal tiene fuerza de ley (Gesetzeskraft), para añadir en su inciso segundo que la tendrá igualmente cuando el Tribunal declare una ley compatible o incompatible con la Ley Fundamental o bien nula ("wenn das Bundesverfassungsgericht ein Gesetz als mit dem Grundgesetz vereinbar oder unvereinbar oder für nichtig erklärt wird"), diferenciación que se reitera en el inicio del inciso inmediato posterior del mismo apartado.

Basta con lo hasta aquí expuesto para que ya pueda comprenderse que no siempre es posible diferenciar con precisión las Appellentscheidungen de las declaraciones de inconstitucionalidad sin pronunciamiento de nulidad (Unvereinbarkeitserklärung). Como bien se ha indicado ${ }^{96}$, la simple determinación para que el legislador regule una determinada materia dentro de un cierto plazo (o, añadiríamos por nuestra cuenta, sin fijación de plazo alguno) no expresa un rasgo exclusivo del primer tipo de decisiones, en tanto en cuanto también en las que ahora analizamos se recogen, en bastantes ocasiones, recomendaciones o exhortaciones expresas para que el legislador promulgue una nueva ley o modifique la fiscalizada en sede constitucional.

Ahora bien, dicho lo que antecede, conviene hacer una puntualización. Ya con anterioridad pusimos de relieve que las Appellentscheidungen pueden considerarse una modalida particular de sentencias desestimatorias, y en ello difieren de modo radical de las ahora contempladas, pues las Unvereinbarkeitserklärung son sentencias declaratorias de la inconstitucionalidad, aunque rompan con el binomio tradicional inconstitucionalidad/nulidad. De esta por lo demás obvia diferencia ha extraído Ipsen una divergencia adicional: mientras las decisiones de apelación al legislador tienen un contenido preventivo, operando en el "campo preliminar de la patología constitucional", la declaración de inconstitucionalidad sin pronunciamiento de nulidad, por el contrario, tiene un carácter prescriptivo, obligando al legislador a suprimir, con la mayor presteza posible, la situación de inconstitucionalidad ${ }^{97}$.

96 Gilmar FerReira Mendes: "O apelo ao legislador...”, op. cit., pág. 279.

97 Jörn IPSEN: Rechtsfolgen der Verfassungswidrigkeit von Norm und Einzelakt, Nomos, Baden-Baden, 1980, págs. 268-269. Cit. por Gilmar Ferreira Mendes: "O Apelo ao legislador...", op. cit., pág. 281. 
Las múltiples posibilidades que este tipo de resoluciones ofrecen iban a ser puestas de relieve por la doctrina. Tal sería el caso de Schlaich y Korioth, para quienes ${ }^{98}$ en la figura de las leyes incompatibles ("von der Figur des 'unvereinbaren' Gesetzes") se ve tan sólo un pequeño paso ("ein kleiner Schritt") hacia unas ulteriores variantes de veredictos en las resoluciones ("zu einer weiteren Spielart von Entscheidungsaussprüchen").

II. Las declaraciones de mera incompatibilidad, como ya se ha dicho, responden primigeniamente a la hipótesis de una exclusión arbitraria de beneficio, que obviamente es incompatible con el principio de igualdad, al otorgar ventajas o beneficios a ciertos grupos o segmentos sociales, excluyendo de las mismas, de modo expreso o implícito, a otros grupos o segmentos que se hallan en iguales condiciones. Como se puede inferir de todo lo expuesto precedentemente, en muchos de estos supuestos la exclusión es el resultado de una omisión legislativa, lo que nos sitúa ante una omisión relativa o parcial.

La decisión de 11 de junio de 1958 puede citarse como paradigmática ${ }^{99}$. A través de una ley de 6 de diciembre de 1951, los sueldos de los funcionarios y las pensiones de jubilación de antiguos miembros de la función pública fueron incrementados un 20 por 100 con efectos del $1 .^{\circ}$ de octubre. El aumento no se extendió, sin embargo, a las prestaciones que percibían una categoría de antiguos funcionarios (aquellos que el 8 de mayo de 1945 no habían sido repuestos en una situación de actividad o no habían encontrado una función equivalente a la de su antiguo estatuto funcionarial). Ante tal situación, varios recursos de queja constitucional fueron presentados por miembros de estas categorías, demandando la anulación de la ley de 1951 en base a que había llevado a cabo una discriminación injustificada entre diversas categorías de jubilados y pensionistas de la función pública.

El BVerfG iba a constatar que la nulidad no podía aquí ser una sanción apropiada frente a la eventual inconstitucionalidad, pues supondría tan sólo la abrogación de la base legal de los sueldos de la función pública, mientras que la misma Grundgesetz requería el mantenimiento de tal fundamento legal. Por otro lado, la declaración de nulidad en nada absolutamente beneficiada a los demandantes en queja.

El Tribunal Constitucional no iba a apreciar una lesión del principio de igualdad, pero sí, por el contrario, del art. 33.5 GG, en cuya virtud, el Derecho de la función pública ("Das Recht des öffentlichen Dienstes") debía ser regulado teniendo en cuenta "los principios tradicionales del funcionariado" ("der hergebrachten Grundsätze des Berufsbeamtentums"), pues en cuanto los aumentos salariales tan sólo pretendían otorgar a los funcionarios en activo o jubilados un standard mínimo de vida, la privación del aumento a las mencionadas categorías privaba a sus integrantes del mínimo constitucionalmente requerido.

98 Klaus SCHLAich y Stefan KORIOTH: Das Bundesverfassungsgericht. Stellung, Verfahren, Entscheidungen, op. cit., pág. 290.

99 Cfr. al efecto, Jean-Claude BÉGuin: Le contrôle de la..., op. cit., págs. 239-241. 
Constatada la violación de derechos fundamentales de los demandantes en queja, el Tribunal soslayaba la anulación de los preceptos legales, a fin de evitar un vacío jurídico conducente a privar de base legal el pago de los sueldos y pensiones de los funcionarios, base legal, como acaba de decirse, exigida constitucionalmente por el mencionado art. 33.5 GG. Así las cosas, el BVerfG se limitaba simplemente a constatar que el legislador federal, al abstenerse de modificar (de incrementar en realidad) ciertos sueldos y pensiones, había atentado contra un derecho garantizado por el art. 33.5 GG, decisión que tenía como efecto desencadenar la obligación del legislador de adoptar en beneficio del grupo concernido una ley conforme con las exigencias constitucionales del art. 33.5.

Si la técnica de la declaración de nulidad es perfectamente válida para hacer frente a una inconstitucionalidad por acción, en casos como el comentado, en los que es la omisión parcial del legislador la desencadenante de la inconstitucionalidad, resulta patente lo inapropiado de tal técnica para reparar los perjuicios causados. Difícilmente la nulidad propiciará el restablecimiento del orden constitucional violado por la omisión relativa del legislador.

III. Un segundo factor proclive a este tipo de decisiones es la salvaguarda de la libertad de configuración del legislador. Pestalozza lo expresa claramente cuando alude a una segunda justificación de renuncia a la técnicamente posible ("technisch mögliche") declaración de nulidad: el respeto a la libertad de configuración del legislador en el marco del art. 3. .1 GG ("die Rücksichtnahme auf die sog. "Gestaltungsfreiheit des Gesetzgebers" in Rahmen des Art. 3 I GG") a través de la declaración de incompatibilidad ${ }^{100}$. Es ésta, por lo demás, una opinión ampliamente compartida por la doctrina germana, pero no sólo por ella, también por la foránea. Así, Crisafulli sostiene ${ }^{101}$ que esta variante de decisión tiene la finalidad de dejar plenamente libre al poder legislativo en la elección de los modos con los que hacer cesar la comprobada vulneración de la Constitución ${ }^{102}$. La libertad de configuración del legislador ha pasado a ser casi una especie de cláusula general para justificar la aplicación de la declaración de inconstitucionalidad sin un pronunciamiento de nulidad $^{103}$, con base en que tal libertad exige que sea el poder legislativo el que decida acerca de las posibles alternativas en presencia para la eliminación de la inconstitucionalidad.

100 Christian Pestalozza: Verfassungsprozeßrecht, op. cit., pág. 344.

101 Vezio Crisafulli: "Giustizia costituzionale e potere legislativo", en Aspetti e tendenze del Diritto costituzionale. Scritti in onore di Costantino Mortati, Giuffrè, Milano, 1977, vol. 4. ${ }^{\circ}$, págs. 129 y ss.; en concreto, pág. 141.

102 Análoga posición mantienen, entre otros, Angelo Antonio CervaTI: "Incostituzionalità delle leggi ed efficacia delle sentenze delle Corti costituzionali austriaca, tedesca ed italiana", en Quaderni Costituzionali, anno IX, n. ${ }^{\circ}$ 2, Agosto 1989, págs. 257 y ss.; en concreto, pág. 270. Asimismo, Jean-Claude BéGuin: Le contrôle de la constitutionnalité des lois..., op. cit., págs. 250 y ss. Y también Wolfgang ZeIDLER: "Cour constitutionnelle fédérale allemande", op. cit., pág. 49.

103 Gilmar FerReira Mendes: Jurisdição Constitucional, op. cit., págs. 275-276. 
No han faltado, sin embargo, críticas frente a tal argumento, al entender algunos sectores de la doctrina ${ }^{104}$ que la libertad de configuración del legislador no se ve afectada en la mayoría de los casos, en tanto en cuanto el poder legislativo puede dictar normas tanto después de una declaración de nulidad cuanto tras una declaración de mera incompatibilidad o inconstitucionalidad.

La sentencia de 15 de febrero de $1967^{105}$ puede ejemplificar estos casos. La ley de 16 de agosto de 1961, sobre la profesión de consejero o consultor fiscal, declaró incompatible con la práctica de esta profesión el ejercicio de una actividad comercial o industrial o de una actividad asalariada, con las salvedades que la propia ley determinaba. Dos recursos de queja constitucional desencadenaban el pronunciamiento del Tribunal Constitucional Federal. Para éste, las normas de incompatibilidad no eran "per se" desproporcionadas, pero eran formuladas sin restricción alguna, de modo que se aplicaban incluso a las personas que habían venido ejerciendo hasta ese mismo momento una actividad comercial además de su profesión de asesor fiscal, ejercicio que, en ocasiones, se realizaba desde largo tiempo atrás. La obligación de escoger entre una u otra actividad no era previsible para tales personas, circunstancia de la que, a juicio del BVerfG, resultaba una sensible limitación de su derecho fundamental al libre ejercicio de una profesión, garantizado por el art. 12.1 GG ("Alle Deutschen haben das Recht, Beruf, Arbeitsplatz und Ausbildungsstätte frei zu wählen": "Todos los alemanes tienen derecho a elegir libremente su profesión, su lugar de trabajo y su lugar de formación").

Entiende el Tribunal que en la medida en que la obligación de abandonar de inmediato una actividad comercial o industrial sería, para las personas concernidas, excesiva a la vista del principio de proporcionalidad, el legislador debe adoptar una reglamentación transitoria cuya forma y diseño ha de ser dejada a su propia apreciación, aunque el Tribunal señala que la antigüedad en el ejercicio de la profesión, la naturaleza e importancia económica de la actividad comercial e industrial, la edad del interesado y las posibilidades de retirarse de sus negocios sin pérdidas, pueden ser elementos a tomar en consideración.

Otro ejemplo nos puede venir dado por la sentencia de 11 de mayo de 1970. El Tribunal Constitucional Federal había sido instado por el Bundesfinanzhof (Tribunal Federal de Hacienda) a que se pronunciara sobre la constitucionalidad de la ley de 23 de septiembre de 1958, relativa al impuesto sobre la renta, de acuerdo con la cual, las plusvalías obtenidas por la venta de un terreno no se hallaban comprendidas dentro de la base imponible, esto es, sujeta al impuesto, de un agricultor. El BVerfG entiende que, en el marco de pág. 44.

104 Cfr. al efecto Jörn IPSEN: "Nichtigerklärung oder "Verfassungswidrigerklärung”...”, op. cit.,

105 Cfr. al respecto, Jean-Claude BÉGuin: Le contrôle de la constitutionnalité des lois..., op. cit., págs. 257-258. 
su política agrícola, el legislador podía conceder ciertas ventajas a los agricultores, precisando que no pertenecía al Tribunal controlar si el legislador había adoptado la solución más justa, apropiada y racional. Era claro, pues, que una intervención selectiva del Estado bajo la forma de una exoneración fiscal no suponía sin más una ruptura del principio de igualdad. Ahora bien, el BVerfG precisaba que debía velar para que tal exoneración fiscal se aplicara a situaciones de hecho equivalentes.

Admite el Tribunal que pertenece a los órganos legislativos definir las condiciones en las que los hándicaps económicos de la agricultura pueden ser compensados a través de ventajas fiscales, por ejemplo, cuando los terrenos permanecen dedicados al uso agrícola. Pero cuando no es éste el caso, por ejemplo, con la urbanización de esos terrenos, el privilegio ya no se halla justificado. Es por lo mismo por lo que el BVerfG cuestiona el privilegio indiferenciado ("unterschiedslose Privilegierung») previsto por el legislador.

La referida exoneración fiscal se presentaba en el texto legal bajo la forma de una disposición expresa y diferenciada. Su anulación era perfectamente posible, pero conducía a la desaparición del conjunto de un régimen fiscal que, en sí mismo, no era inconstitucional. Por otro lado, el legislador podía restablecer la igualdad de diferentes modos: descartando pura y simplemente tal régimen exoneratorio, pero también precisando las condiciones en que el mismo podía aplicarse. En coherencia con todo ello, el BVerfG declaraba la disposición fiscalizada incompatible con el art. 3. ${ }^{\circ} .1 \mathrm{GG}$, si bien no daba ninguna directriz al órgano que había planteado la cuestión de constitucionalidad, el Bundesfinanzhof. Este sorprendente silencio, como recordaba Béguin $^{106}$, desencadenaría una notable controversia sobre las consecuencias de una declaración de mera incompatibilidad, o lo que es lo mismo, de inconstitucionalidad sin nulidad. Tampoco debe extrañar ahora en exceso tal circunstancia, pues, con una perspectiva amplia, la actuación del BVerfG nos muestra que en aquellos supuestos en que el principio de igualdad ha sido infringido y en los que el restablecimiento del mismo, a través de la extensión del privilegio o beneficio concedido inicialmente a tan sólo unos sectores de individuos, entraña unas consecuencias presupuestarias relevantes, por el incremento que supone para el erario público la ampliación del beneficio, el Tribunal Constitucional se ha mostrado sensible a tal circunstancia, operando la misma, de modo más o menos explícito, como un argumento más para deferir al legislador la formulación del diseño legal que estime más apropiado a la vista de todos los elementos en presencia.

En último término, creemos de interés poner de relieve que, como regla general, y ello ya ha quedado implícito en alguno de los casos comentados, la omisión legislativa ha asumido un rol relevante para la fundamentación de la declaración de inconstitucionalidad sin nulidad. Se han subrayado incluso las semejanzas de algunos supuestos con los presupuestos de una omisión ab-

106 Jean-Claude BéGuin: Le contrôle de la constitutionnalité des lois en République Fédérale d'Allemagne, op. cit., pág. 262. 
soluta o total ${ }^{107}$. Y en tales casos omisivos, el Tribunal Constitucional Federal se ha venido absteniendo de declarar la nulidad con base en la consideración de que la transgresión constitucional derivaba no de la regulación, sino, normalmente, de su incomplitud, circunstancia a la que se reconducía tanto la omisión del desarrollo del complejo normativo, como la exclusión arbitraria de beneficio.

IV. Llegados aquí, es el momento de que nos centremos en las consecuencias jurídicas de las decisiones de que nos estamos ocupando.

En su análisis sobre el dilema en la praxis del control normativo de constitucionalidad entre las declaraciones de inconstitucionalidad y de nulidad, Ipsen comienza poniendo de relieve cómo un "dogma inamovible" (unverrückbares Dogma") como era el de la nulidad de las normas inconstitucionales ("die Nichtigkeit der verfassungswidrigen Norm") ha evolucionado en la jurisprudencia del Tribunal a través de un laberinto dogmático ("einem dogmatischen Laberynth") hasta llegar al extremo de que las consecuencias jurídicas de la inconstitucionalidad de las normas ("die Rechtsfolgen des Verfassungswidrigkeit von Normen") son determinadas por el propio Tribunal Constitucional nach Ermessen, esto es, a través de su libre albedrío ${ }^{108}$, por todo lo cual el propio autor concluye que estamos en presencia de "eine genuin richterrechtliche Figur" ${ }^{109}$ (una genuina figura jurídica judicial). Este carácter ciertamente peculiar y genuino podría entrelazarse, y así lo hace Cervati $^{110}$, con la pauta tendencial que, desde tiempo atrás, se puede apreciar en la jurisprudencia de los Tribunales Constitucionales europeos, a desarrollar de modo flexible el propio control de constitucionalidad, y ello no sólo al nivel de la interpretación de los parámetros constitucionales, cada vez más elásticos y vinculados con las situaciones de hecho, sino también con referencia al tipo de dispositivo al que vienen recurriendo de vez en cuando.

No puede extrañar, a la vista de lo que se acaba de decir, que no siempre sean del todo claras las consecuencias jurídicas de la declaración de mera incompatibilidad o de inconstitucionalidad sin nulidad. Abona tal circunstancia el hecho de que esos efectos no pueden ser inferidos directamente de la BVerfGG. La ley, en efecto, tan sólo prevé en su art. 79 que contra una sentencia penal firme ("gegen ein rechtskräftiges Strafurteil») que se base en una norma declarada incompatible con la Grundgesetz o en una interpretación considerada por el BVerfG como incompatible con la Ley Fundamental, cabrá recurso de revisión de conformidad con lo dispuesto por el ordenamiento procesal penal (o criminal) («trafprozeßordnung"). Tal determinación, aunque circunscrita al proceso penal, parece mostrar un deseo implícito del legislador

107 Gilmar FerReira Mendes: Jurisdição Constitucional..., op. cit., págs. 274-275.

108 Jörn IPSEN: “Nichtigerklärung oder "Verfassungswidrigerklärung»...”, op. cit., pág. 41.

109 Ibidem, pág. 41.

110 Antonio Cervati: "Tipi di sentenze e tipi di motivazioni nel giudizio incidentale di costituzionalità delle leggi", en la obra colectiva, Strumenti e tecniche di giudizio della Corte costituzionale (Atti del Convegno. Trieste 26-28 maggio 1986), Giuffrè Editore, Milano, 1988, págs. 125 y ss.; en concreto, págs. 133-134. 
de que una norma declarada en sede constitucional incompatible con la Ley Fundamental, aun cuando no invalidada, no sea aplicada. En cualquier caso, las consecuencias jurídicas de la declaración de inconstitucionalidad sin nulidad siguen sin ser del todo claras, e incluso, como apunta Schlaich ${ }^{111}$, en casos concretos, conducen a incertidumbres apenas soportables en lo referente a la situación jurídica transitoria.

La praxis muestra que en su primera jurisprudencia el BVerfG consideró admisible la aplicación provisional de una ley declarada incompatible con la Constitución. Ciertamente, esta doctrina iba a cambiar en la relevante sentencia relativa a la nacionalidad de los hijos provenientes de los llamados "matrimonios mixtos", en la que el Tribunal Constitucional vino a equiparar, en lo relativo a la aplicación de la ley declarada incompatible con la Grundgesetz, la declaración de inconstitucionalidad sin nulidad a la declaración de nulidad. Dicho de otro modo, la ley considerada incompatible con la Grundgesetz, lisa y llanamente, no puede ser aplicada. Sin embargo, esta regla general no dejó de tener alguna excepción, en particular, cuando la inaplicación generase un vacío jurídico intolerable para el ordenamiento constitucional. Y así, en la sentencia precedentemente aludida, el BVerfG consideró que la inaplicación de la ley reguladora del régimen jurídico que debía aplicarse respecto a la nacionalidad de los hijos de matrimonios mixtos generaba un vacío legislativo que propiciaba una situación aún más alejada de la voluntad constitucional de la que se producía de resultas de su aplicación. En definitiva, la posición del BVerfG puede compendiarse ${ }^{112}$ en la idea de que el Tribunal admite la legitimidad de la aplicación provisional de la ley declarada incompatible con la Grundgesetz si razones de índole constitucional y, en particular, motivos de seguridad jurídica, convierten en imperiosa la vigencia temporal de la ley inconstitucional.

La situación que genera la aplicación de una ley ya expresamente declarada inconstitucional no deja de ser paradójica, aun cuando se pueda considerar asentada en el genérico argumento del "mal menor". Con todo, la doctrina alemana, por lo general, se ha mostrado de acuerdo con esta situación. Pestalozza precisa al respecto que la jurisprudencia constitucional muestra ampliamente que la vigencia de las normas inconstitucionales ("die Geltung verfassungswidriger Normen") debe ser derivada del sistema jurídico ("aus dem Rechtssystem abzuleiten") y no de un orden independiente ("nicht auf eine selbständige "Anordnung"») que se deba al Tribunal Constitucional Federal $^{113}$. No se puede decir otro tanto de la doctrina foránea, entre la que este tipo de decisiones no deja de suscitar algunas formulaciones críticas. Este sería el caso, por poner un ejemplo, de Elia, para quien la lógica continuidad de

111 Klaus SCHLAich: "El Tribunal Constitucional Federal Alemán”, op. cit., pág. 198.

112 Gilmar FerReIRA MENDEs: Jurisdição Constitucional. O controle abstrato de normas no Brasil e na Alemanha, op. cit., pág. 286.

113 Christian PESTALOzZA: "Noch verfassungsmäßige" und "bloß verfassungswidrige" Rechtslagen", op. cit., págs. 565-566. 
la aplicación parcial de la ley inconstitucional denuncia la falta de lógica («illogicità"), la íntima contradicción ("contraddittorietà") de la solución acogida por el Tribunal de Karlsruhe ${ }^{114}$.

Al margen ya de la salvedad precedentemente señalada, la regla general es que la declaración de inconstitucionalidad, aún sin el pronunciamiento de nulidad, impide que los tribunales o que la Administración puedan aplicar la ley en cuestión. Puede hablarse, pues, de un efecto de suspensión o bloqueo de la aplicación de la norma (Anwendungssperre), aunque la misma no quede eliminada del ordenamiento jurídico. Ipsen, que, como ya se dijo, en un determinado momento habla de una "paralización jurídica por razón de Estado" ("Rechtsstillstand aus Staatsräson"), considera ${ }^{115}$ que la suspensión de la aplicación de la norma (Normenwendungssperre) debe entenderse no como una precaución o cautela para situaciones de excepción, sino como una consecuencia jurídica dimanante de la declaración de inconstitucionalidad ("Rechtsfolge der Verfassungswidrigerklärung"). No se puede olvidar al respecto algo a lo que ya aludimos, que el art. 31.2 BVerfGG otorga "fuerza de ley" (Gesetzeskraft") a la sentencia en los casos de los recursos de queja constitucional (Verfassungsbeschwerde), cuando la misma declare incompatible (unvereinbar) con la Ley Fundamental una determinada ley. No hay, pues, en relación a este efecto, diferencia alguna entre las resoluciones que declaren la compatibilidad, la mera incompatibilidad o la nulidad de la ley impugnada a través del Verfassungsbeschwerde. Ello se traduce a su vez en la paralización de los procesos pendientes ante los tribunales ordinarios de justicia. Esta suspensión del proceso debe perdurar hasta tanto el legislador proceda a dictar un nuevo texto legal o a reformar el tildado de incompatible con la Grundgesetz.

La consecuencia jurídica más relevante de este tipo de decisiones es, obviamente, la imposición al legislador de la obligación de suprimir la situación inconstitucional. Como escriben Schlaich y Korioth ${ }^{116}$, "das BVerfG verbindet seine Feststellung mit dem Appell an den Gesetzgeber zu handeln" (el Tribunal Constitucional Federal une su declaración con la apelación a actuar al legislador). Tal apelación puede complementarse con la formulación de un mandato constitucional ("zur Formulierung eines Verfassungsauftrags") o incluso con la fijación de un plazo ("einer Fristsetzung"). Como es obvio, el transcurso del tiempo concedido al legislador sin que éste proceda a cumplir con su deber de legislar, se nos antoja un supuesto más teórico que real, aunque es evidente que, de producirse, no podría dejar de tener consecuencias jurídicas de ser instado el BVerfG a pronunciarse al respecto, en cuyo caso la

114 Leopoldo Elia: "Le sentenze additive e la piú recente giurisprudenza della Corte costituzionale (ottobre 81 - luglio 85)", en Scritti su la Giustizia Costituzionale. In onore di Vezio Crisafulli, CEDAM, Padova, 1985, vol. I, págs. 299 y ss.; en concreto, pág. 309.

115 Jörn IPSEN: "Nichtigerklärung oder "Verfassungswidrigerklärung" — Zum Dilemma der verfassungsgerichtlichen Normenkontrollpraxis", op. cit., pág. 44.

116 Klaus Schlaich y Stefan Korioth: Das Bundesverfassungsgericht. Stellung, Verfahren, Entscheidungen, op. cit., pág. 293. 
respuesta lógica habría de ser la total invalidación de la ley previamente tildada de incompatible con la Grundgesetz.

Un sector de la doctrina ha equiparado la situación que, en ocasiones, puede crear estas decisiones al efecto que la legislación austriaca posibilita al prever una vacatio sententiae. Y así, Schlaich, refiriéndose a la sentencia relativa a la admisión en establecimientos de enseñanza superior, pone de relieve que la decisión del Tribunal de considerar que el art. 17 de la Ley de Universidades era incompatible con la Grundgesetz, precisando de inmediato que, ello no obstante, debía ser aplicado hasta la elaboración de una nueva regulación legislativa y fijando el plazo en que la misma debía ser aprobada, recuerda la solución austriaca ${ }^{117}$. También D'Orazio, entre la doctrina foránea, se sitúa en esta línea de pensamiento, considerando que la disociación (lógica y cronológica) de los dos momentos (el de la incompatibilidad y el de la nulidad) en la jurisprudencia del BVerfG equivale, sustancialmente, a la vacatio sententiae austriaca ${ }^{118}$. Y entre nosotros, Rubio Llorente entiende que este modo de operar del Tribunal Constitucional Federal entraña un regreso a la vieja fórmula austriaca de diferir la eficacia de la declaración de nulidad para que el legislador pueda mientras tanto obrar en consecuencia, si bien hay una divergencia que no puede dejar de ser tenida en cuenta: en tanto que en Austria esta solución, prevista constitucionalmente, resulta perfectamente coherente con la teoría del legislador negativo, cuyas decisiones son constitutivas y operan ex nunc, es difícil justificarla en un sistema en el que se atribuye a las decisiones del juez constitucional naturaleza declarativa y eficacia ex tunc ${ }^{119}$.

Bien significativo de la proximidad de la solución jurisprudencialmente asumida por el BVerfG a la fórmula austriaca es el hecho de que entre $1969 \mathrm{y}$ 1970 se intentara la reforma del art. 79 BVerfGG, al que ya hemos aludido, precepto que regula algunos de los efectos de estas decisiones, con la finalidad de aproximar esta disposición a la fórmula austriaca ${ }^{120}$, reforma que finalmente sería rechazada por el Bundestag, que, como ya se expuso, en 1970, se limitó a admitir la alternativa entre la inconstitucionalidad con nulidad o sin ella.

117 Klaus Schlaich: «El Tribunal Constitucional Federal Alemán”, op. cit., págs. 197-198.

118 Giustino D’OrAzIO: "Aspectos y problemas de la justicia constitucional italiana", en Revista Vasca de Administración Pública, n. ${ }^{\circ}$ 31, Septiembre/Diciembre 1991, págs. 59 y ss.; en concreto, pág. 91.

119 Francisco RuBio LLORENTE: «La jurisdicción constitucional como forma de creación de Derecho", en Revista Española de Derecho Constitucional, n. ${ }^{\circ} 22$, Enero/Abril 1988, págs. 9 y ss.; en concreto, págs. 36-37.

120 La reforma pretendía introducir un nuevo primer párrafo en el art. 79 BVerfGG del siguiente tenor: "El Tribunal Constitucional Federal, por graves motivos de interés público, podrá establecer en su decisión que una ley declarada nula continúe en vigor hasta el momento en que la decisión judicial haya determinado su pérdida de vigencia. Este término no puede ser posterior a la producción de los efectos de la decisión". Cfr. al efecto, María Jesús MonToro Chiner: "Protección de la familia y fiscalidad (A propósito de la STC 45/1989, de 20 de febrero)", en Revista Española de Derecho Constitucional, n. ${ }^{\circ} 28$, Enero/Abril 1990, págs. 223 y ss.; en concreto, págs. 228-229. 
En fin, de la relevancia que esta técnica decisoria adquirió en la vida del Tribunal Constitucional Federal da buena prueba el hecho de que en el lapso de tiempo que va de 1970 a 1982 el número de declaraciones de mera inconstitucionalidad y el de nulidad eran equivalentes ${ }^{121}$, lo que revela el notabilisímo crecimiento de las Unvereinbarkeitserklärung, particularmente tras su positivación en 1970.

\section{LAS DECISIONES INTERPRETATIVAS O DE INTERPRETACIÓN CONFORME A LA CONSTITUCIÓN («VERFASSUNGSKONFORME AUSLEGUNG")}

I. El BVerfG, como la práctica totalidad de órganos equivalentes, hizo suya desde los primeros momentos la técnica decisoria de la interpretación conforme a la Constitución (Verfassungskonforme Auslegung), que ya era conocida por la Supreme Court, y de la que se ha dicho que también lo fue en la época de Weimar ${ }^{122}$.

El BVerfG también se vale de esta técnica para hacer frente a ciertas omisiones legislativas. Este tipo de decisiones es sobradamente conocido y, además, es obvio que presenta un interés menor que las anteriormente examinadas a los efectos de la cuestión que venimos tratando. Por lo mismo, le dedicaremos tan sólo una muy superficial atención.

Es bien sabido que esta técnica entraña que una disposición susceptible de interpretación sólo pueda ser declarada inconstitucional cuando ninguna de las interpretaciones posibles, o si se prefiere, ninguna de las normas extraíbles por vía hermenéutica de tal disposición sea conforme a la Constitución. Como hace ya más de cuarenta años señalara Crisafulli, y su reflexión tiene plena actualidad, las sentencias interpretativas requieren utilizar la distinción conceptual entre "disposición" y "norma", como producto o resultado esta última de la interpretación de los textos en estrecha conexión con el entero sistema del Derecho objetivo ${ }^{123}$.

121 Klaus ScHLAICH: "Corte costituzionale e controllo sulle norme nella Repubblica Federale di Germania", op. cit., pág. 575.

122 Se ha señalado por Flad que ya en Weimar, en relación al control abstracto del Derecho de los Länder, al amparo del párrafo segundo del art. 13 de la Constitución de 1919, que contemplaba el que podríamos llamar "control de federalidad", se percibió que cuando una disposición de un Land que pareciese válida en sí misma, mostrase que una de sus aplicaciones pudiese revelarse inconstitucional, sería legítimo declarar la incompatibilidad de esa aplicación de la disposición jurídica del Land respecto del Derecho federal. Flad apunta incluso a la decisión del Reichsgericht de 29 de mayo de 1923, en la que, a su juicio, el Tribunal habría declarado expresamente la inconstitucionalidad de una determinada aplicación de la norma jurídica de un Land. Wolfgang FlaD: Verfassungsgerichtsbarkeit und Reichsexecution, Heidelberg, 1929, pág. 43. Cit. por Gilmar FERREIRA MENDES: Jurisdição Constitucional..., op. cit., pág. 288, nota 224.

123 Vezio CRISAFULLI: "Le sentenze "interpretative" della Corte costituzionale", en Rivista trimestrale di Diritto e procedura civile, anno XXI, n. ${ }^{\circ}$ 1, Marzo 1967, págs. 1 y ss.; en concreto, pág. 2. 
El principio de la interpretación conforme hunde sus raíces en el principio de unidad del ordenamiento jurídico ("Einheit der Rechtsordnung"), pues como dice Hesse ${ }^{124}$, en función de esta unidad las leyes emanadas bajo la vigencia de la Ley Fundamental deben ser interpretadas en consonancia con la propia Grundgesetz. O como desde otra óptica aduce Haak ${ }^{125}$, la interpretación conforme a la Constitución de la ley afecta a la incontrovertibilidad del ordenamiento jurídico ("widerspruchslosigkeit der Rechtsordnung"). En cuanto la Constitución es visualizada como "contexto superior" (vorrangiger Kontext") de las demás normas jurídicas, las leyes y restantes disposiciones infralegales han de ser interpretadas forzosamente en consonancia o conformidad con la Constitución.

La interpretación conforme a la Constitución es, obviamente, interpretación ${ }^{126}$, lo que se traduce en que uno de los límites de esta técnica se encuentra en el sentido literal inequívoco ( «im eindeutiger Wortsinn") ${ }^{127}$; dicho de otro modo, sólo cuando exista una "res dubia" cabrá recurrir a este principio ${ }^{128}$, y en pura lógica, la interpretación debe de conducir a un resultado inequívoco. La equivocidad del sentido de la disposición que posibilita la Verfassungskonforme Auslegung se manifiesta lógicamente en que la disposición legal se interpreta de modo diferenciado: por un lado, hay una interpretación en armonía con la Constitución ("einen Auslegung in Einklang mit der Verfassung"), y por otro, puede propiciar una contradicción con ella ("Widerspruch zu ihr") ${ }^{129}$. De ahí que a través de la interpretación conforme a la Constitución determinadas "posibilidades interpretativas" ("Auslegungsmöglichkeiten"), por utilizar la expresión de Schlaich y Korioth ${ }^{130}$, puedan ser declaradas inconstitucionales. Quizá por ello, algún autor, como es el caso de Zeidler, entienda que la interpretación conforme a la Constitución presenta analogías funcionales con la de-

124 Konrad Hesse: Escritos de Derecho Constitucional, Centro de Estudios Constitucionales, Madrid, 1983, págs. 54-55.

125 Volker HAAK: Normenkontrolle und verfassungskonforme Gesetzesauslegung des Richters, Ludwig Röhrscheid Verlag, Bonn, 1963, pág. 304.

126 "Verfasssungskonforme Auslegung —escriben Schlaich y Korioth— ist also Auslegung". Klaus Schlaich y Stefan Kоrioth: Das Bundesverfassungsgericht. Stellung, Verfahren, Entscheidungen, op. cit., pág. 296.

127 Volker HAAK: Normenkontrolle und verfassungskonforme..., op. cit., pág. 304. Haak alude a otro límite de este principio: la tendencia histórica de las leyes ("der historischen Tendenz des Gesetzes").

128 El Tribunal Constitucional Federal ha consagrado esta orientación en la medida en que reconoce que la expresión literal impone un límite a la interpretación conforme. Por otro lado, Ferreira Mendes recuerda (en Jurisdição Constitucional..., op. cit., pág. 290) que el BVerfG, siguiendo una orientación jurídico-funcional, ha entendido que también los propósitos perseguidos por el legislador imponen límites a la interpretación conforme, lo que no puede considerarse sino como una manifestación más del principio de la autolimitación judicial (judicial self-restraint), al que ya hemos tenido oportunidad de referirnos.

129 Reinhold ZipPELIUS: "Verfassungskonforme Auslegung von Gesetzen", en Bundesverfassungsgericht und Grundgesetz (Fetsgabe aus Anlaß des 25 jährigen Bestehens des Bundesverfassungsgerichts), herausgegeben von Christian STARCK, Zweiter Band (volumen segundo), J.C.B. Mohr (Paul Siebeck), Tübingen, 1976, págs. 108 y ss.; en concreto, pág. 108.

130 Klaus Schlaich y Stefan Korioth: Das Bundesverfassungsgericht..., op. cit., pág. 266. 
claración de nulidad parcial de una norma, aunque la misma evite justamente la declaración de nulidad de la disposición legal ${ }^{131}$.

Se admite de modo generalizado que el principio que nos ocupa se vincula estrechamente con el principio de conservación de la norma, con el que se trata de compatibilizar la primacía de la Constitución y la salvaguarda, allí hasta donde sea posible, de la voluntad del legislador. El respeto al legislador, que en cada momento histórico actualiza la voluntad soberana del pueblo, y la confianza acerca de su observación y correcta interpretación de los principios constitucionales, subyacen en la Verfassungskonforme Auslegung. En esta misma dirección, Zippelius habla del argumento del favor legis. A su juicio, un argumento adicional para una interpretación conforme a la Constitución se deriva desde el punto de vista del control normativo ("der Sicht der Normenkontrolle"). Desde esta óptica, una norma tiene validez ("Gültigkeit") en su interpretación cuando la misma puede existir junto a la Constitución sin contradicción $^{132}$.

También Simon admite ${ }^{133}$ que esta perspectiva hermenéutica fue desarrollada al servicio del mantenimiento de las normas y de la autoridad del legislador, si bien — precisa de inmediato- ilustra asimismo la ambivalencia de los esfuerzos por respetar el ámbito de otros órganos del Estado, ya que fuerza a la interpretación del Derecho ordinario y, de esa forma, se inmiscuye en la función de los jueces y tribunales, pudiendo asimismo llegar a deformar la auténtica voluntad del legislador con la preferencia por determinadas fórmulas que el legislador hubiera podido establecer. La elección del Tribunal Constitucional, que a veces puede acontecer de modo "acrobático", por utilizar los términos de Stern, hace surgir las dudas acerca de si el legislador es realmente más tutelado a través de esta técnica. Existe el peligro, dirá de nuevo Schlaich ${ }^{134}$, de que una interpretación conforme a la Constitución interfiera en mayor medida en la libertad legislativa de lo que lo puede hacer la declaración de nulidad.

El BVerfG, como antes de dijo, se vale de esta técnica hermenéutica para rellenar, dicho impropiamente, las lagunas generadas, entre otras causas, por las omisiones legislativas, particularísimamente por las omisiones relativas o parciales. El grupo de casos en que el BVerfG opera así ha sido considerado por Gusy, como también ya se señaló, como ejemplo de una "optimización constitucional" ("verfassungsrechtliche Optimierung») ${ }^{135}$, en cuanto posibilitan una "construcción" en conformidad con la Constitución mediante la ana-

131 Wolfgang ZeidLeR: "Cour constitutionnelle fédérale allemande”, op. cit., pág. 42. En análogo sentido se pronuncia Schlaich, quien no manifiesta duda alguna cuando en relación a este principio escribe: "In realtà si tratta di una dichiarazione di parziale nullità di una legge". Klaus SCHLAICH: "Corte costituzionale e controllo sulle norme...", op. cit., pág. 577.

132 Reinhold Zippelius: "Verfassungskonforme Auslegung von Gesetzen”, op. cit., pág. 110.

133 Helmut SimON: «La Jurisdicción Constitucional”, op. cit., págs. 853-854.

134 Klaus Schlaich: "Corte costituzionale e controllo sulle norme...", op. cit., pág. 576.

135 Christoph Gusy: Parlamentarischer Gesetzgeber und Bundesverfassungsgericht, Berlin, 1985, pág. 214. Cit. por Gilmar FerReIRA MENDEs: Jurisdição Constitucional..., op. cit., pág. 288 
logía, la reducción o a través de la extracción de premisas normativas incuestionables de la propia Ley Fundamental.

La interpretación conforme a la Constitución tiene efectos erga omnes, pues la ley, en el futuro, deberá ser interpretada tal y como ha determinado el BVerfG, y no como parecía inferirse de su propia literalidad. Así lo ha entendido la doctrina ${ }^{136}$, y así lo ha considerado igualmente el Tribunal Constitucional Federal ${ }^{137}$.

II. Hemos de terminar este análisis de la tarea realizada por el BVerfG en relación con las omisiones del legislador. Quizá pueda ser de utilidad, desde una óptica general, recordar la reflexión llevada a cabo por Walter en torno al rol del Tribunal Constitucional Federal en los procesos de cambios constitucionales $^{138}$. Con vistas a reducir la tensión entre normatividad y cambio, el citado autor propone la comprensión del Derecho constitucional desde la perspectiva del proceso de su aplicación por el BVerfG, enfoque que gira en torno al trascendental rol del Tribunal Constitucional Federal en cuanto órgano central de la interpretación constitucional. Y si al Tribunal, hoy, como dice Walter en la conclusión de su trabajo ${ }^{139}$, se encomienda la obligación (“die Aufgabe") de defender la continuidad de la Ley Fundamental ("die kontinuität des Grundgesetzes") frente a las demandas de cambios correspondientes al presente (a la actualidad) ("verändernden Anfragen der jeweiligen Gegenwart"), antaño asumió la labor de acomodar el orden social a los principios y valores constitucionales. No ha de pensarse, ni mucho menos, precisaríamos por nuestra cuenta, que se trate de dos tareas diferenciadas. Bien al contrario, se trata de la misma labor: acomodar las respuestas normativas que los poderes públicos en general y el legislador en particular dan en cada momento, frente a los requerimientos sociales, a los principios y valores constitucionales, interpretados no como un orden estático, sino flexible y evolutivo. En esta tarea, que presupone un recíproco acoplamiento, las técnicas decisorias creadas con gran libertad de criterio por el juez constitucional alemán en respuesta, entre otras demandas, a las exigencias de las omisiones legislativas, aún deudoras de una coyuntura bien distinta, como era la de la sociedad de la postguerra alemana, y, por supuesto, no exentas de aspectos

136 Así, por ejemplo, Klaus Schlaich, en "Corte costituzionale e controllo sulle norme...", op. cit., págs. 576-577.

137 Atendiendo a la jurisprudencia constitucional [BVerfGE 64, 229 (242); 88, 203 (331)] y refiriéndose a la variante de las resoluciones de interpretación de las leyes constitucionalmente conforme ("Entscheidungsvariante der verfassungskonformen Auslegung von Gesetzen"), Weber subraya el principio ("die Grundsätzlich") de que tales resoluciones obligan a todos y cada uno de los jueces ("jedem Richter obliegt") y son preferidas como "interpretación" (und als "Auslegung" zu bevorzugen ist"). Albrecht WEBER: "Die Verfassungsgerichtsbarkeit in der Bundesrepublik Deutschland", en Verfassungsgerichtsbarkeit in Westeuropa, Christian STARCK/Albrecht WeBER (Hrsg.), 2. Auflage, Nomos, Baden-Baden, 2007, págs. 37 y ss.; en concreto, pág. 61.

138 Christian Walter: "Hüter oder Wandler der Verfassung? - Zur Rolle des BVerfG im Prozeß des Verfassungswandels", en Archiv des öffentlichen Rechts (AöR), 125. Band, 2000, Heft 4, págs. 517 y ss.

139 Ibidem, pág. 550. 
críticos, que han sido precedentemente expuestos, creemos que siguen siendo perfectamente válidas, entre otras razones, porque la mutante realidad social sigue planteando nuevos retos jurídicos a los que el legislador no siempre da la adecuada respuesta en tiempo oportuno. Las omisiones del legislador han tenido mucho que ver con estos tipos peculiares de decisiones que contribuyen a mostrarnos con toda crudeza lo lejos que se halla el Tribunal Constitucional Federal del estricto rol kelseniano del legislador negativo.

ABSTRACT. - The evolution of the BVerfG's jurisprudence with regard the control of long-standing legislative inactions it is an excellent example for searching decision's techniques confronted with the problem of the fundamental right's violations as a result of a legislative inaction. The Federal Constitutional Court has created a plurality of decisions by means of them the Court intends to modify particular juridical effects of the constitutional rulings with an object of material and functional justice. The legislative appeal's decisions and the decisions of unconstitutionality without nullity constitute the most original types. 